\title{
Genome-wide analysis of PRR gene family uncovers their roles in circadian rhythmic changes and response to drought stress in Gossypium hirsutum L.
}

\author{
Jingjing Wang Equal first author, 1,2 , Zhaohai Du Equal first author, ${ }^{1}$, Xuehan Huo ${ }^{1,2}{ }^{2}$ Juan Zhou ${ }^{1}$, Yu Chen ${ }^{1}$, Jingxia Zhang ${ }^{1}$, Ao Pan \\ ${ }^{1}$, Xiaoyang Wang ${ }^{3}$, Furong Wang ${ }^{\text {Corresp., 1, } 2, \text { Jun Zhang }}{ }^{\text {Corresp. 1, } 2}$ \\ ${ }^{1}$ Key Laboratory of Cotton Breeding and Cultivation in Huang-Huai-Hai Plain, Ministry of Agriculture and Rural Affairs, Cotton Research Center, Shandong \\ Academy of Agricultural Sciences, Jinan, P. R. China \\ ${ }^{2}$ College of Life Sciences, Shandong Normal University, Jinan, P. R. China \\ ${ }^{3}$ State Key Laboratory of Cotton Biology, Institute of Cotton Research, Chinese Academy of Agricultural Sciences, Anyang, P. R. China \\ Corresponding Authors: Furong Wang, Jun Zhang \\ Email address: wfr1125@126.com, zj0928@126.com
}

Background. The circadian clock not only participates in regulating various stages of plant growth, development and metabolism, but confers plant environmental adaptability to stress such as drought. Pseudo-Response Regulators (PRRs) are important component of the central oscillator (the core of circadian clock) and play a significant role in plant photoperiod pathway. However, no systematical study about this gene family has been performed in cotton.

Methods. PRR genes were identified in diploid and tetraploid cotton using bioinformatics methods to investigate their homology, duplication and evolution relationship. Differential gene expression, KEGG enrichment analysis and qRT-PCR were conducted to analyze PRR gene expression patterns under diurnal changes and their response to drought stress.

Results. A total of 44 PRR family members were identified in four Gossypium species, with 16 in $G$. hirsutum, 10 in G. raimondii, and 9 in G. barbadense as well as in G. arboreum. Phylogenetic analysis indicated that PRR proteins were divided into five subfamilies and whole genome duplication or segmental duplication contributed to the expansion of Gossypium PRR gene family. Gene structure analysis revealed that members in the same clade are similar, and multiple cis-elements related to light and drought stress response were enriched in the promoters of GhPRR genes. qRT-PCR results showed that GhPRR genes transcripts presented four expression peaks ( $6 \mathrm{~h}, 9 \mathrm{~h}, 12 \mathrm{~h}, 15 \mathrm{~h}$ ) during 24 hours and form obvious rhythmic expression trend. Transcriptome data with PEG treatment, along with qRT-PCR verification suggested that members of clade III (GhPRR5a, $b, d)$ and clade V (GhPRR3a and GhPRR3c) may be involved in drought response. This study provides an insight into understanding the function of $P R R$ genes in circadian rhythm and in response to drought stress in cotton. 


\section{Genome-wide analysis of PRR gene family uncovers their roles in}

\section{2 circadian rhythmic changes and response to drought stress in}

\section{Gossypium hirsutum L.}

4 Jingjing Wang ${ }^{1,2}$, Zhaohai $\mathrm{Du}^{1}$, Xuehan $\mathrm{Huo}^{1,2}$, Juan Zhou ${ }^{1}$,Yu Chen ${ }^{1}$, Jingxia Zhang ${ }^{1}$, Ao Pan ${ }^{1}$,

5 Xiaoyang Wang ${ }^{3}$, Furong Wang ${ }^{1,2 *}$, Jun Zhang ${ }^{1,2^{*}}$

6 1. Key Laboratory of Cotton Breeding and Cultivation in Huang-Huai-Hai Plain, Ministry of Agriculture and

7 Rural Affairs, Cotton Research Center, Shandong Academy of Agricultural Sciences, Jinan, P. R. China

8 2. College of Life Sciences, Shandong Normal University, Jinan, P. R. China

9 3. State Key Laboratory of Cotton Biology, Institute of Cotton Research, Chinese Academy of Agricultural

10 Sciences, Anyang, P. R. China

$11{ }^{*}$ Corresponding Author:

12 1. Furong Wang:

$13{ }^{1}$ Gongyebei Road, Jinan, Shandong Province, 250100, China.

142 Wenhuadong Road, Jinan, Shandong Province, 250014, China.

15 E-mail: wfr1125@126.com; wangfurong@shandong.cn

16 2. Jun Zhang:

$17{ }^{1}$ Gongyebei Road, Jinan, Shandong Province, 250100, China.

$182^{2}$ Wenhuadong Road, Jinan, Shandong Province, 250014, China.

19 E-mail: zj0928@126.com; mhzxzhangjun@shandong.cn

20 Abstract

Background. The circadian clock not only participates in regulating various stages of plant growth, development and metabolism, but confers plant environmental adaptability to stress such as drought. PseudoResponse Regulators (PRRs) are important component of the central oscillator (the core of circadian clock) and play a significant role in plant photoperiod pathway. However, no systematical study about this gene family has been performed in cotton.

Methods. $P R R$ genes were identified in diploid and tetraploid cotton using bioinformatics methods to 
27 investigate their homology, duplication and evolution relationship. Differential gene expression, KEGG

28

29

enrichment analysis and qRT-PCR were conducted to analyze $P R R$ gene expression patterns under diurnal changes and their response to drought stress.

Results. A total of 44 PRR family members were identified in four Gossypium species, with 16 in G. hirsutum, 10 in G. raimondii, and 9 in G. barbadense as well as in G. arboreum. Phylogenetic analysis indicated that PRR proteins were divided into five subfamilies and whole genome duplication or segmental duplication contributed to the expansion of Gossypium PRR gene family. Gene structure analysis revealed that members in the same clade are similar, and multiple cis-elements related to light and drought stress response were enriched in the promoters of GhPRR genes. qRT-PCR results showed that GhPRR genes transcripts presented four expression peaks ( $6 \mathrm{~h}, 9 \mathrm{~h}, 12 \mathrm{~h}, 15 \mathrm{~h})$ during 24 hours and form obvious rhythmic expression trend.

Transcriptome data with PEG treatment, along with qRT-PCR verification suggested that members of clade III $(G h P R R 5 a, b, d)$ and clade V $(G h P R R 3 a$ and $G h P R R 3 c)$ may be involved in drought response. This study provides an insight into understanding the function of $P R R$ genes in circadian rhythm and in response to drought stress in cotton.

Keywords: Gossypium hirsutum; PRR family; photoperiod; circadian rhythm; drought response

\section{Introduction}

The circadian clock is an autonomous endogenous biological rhythm that enables the living organisms to adapt to external daily and seasonal cycles, which play a significant role in plant growth and development for plant fitness (Harmer, 2009; Hsu et al., 2014; Lee et al., 2005; McClung, 2006; Uehara et al., 2019) Although the circadian clock in different organisms is tissue-specific, most organisms have a conserved molecular mechanism-the core oscillator of positive and negative feedback loops formed at both the transcriptional and translational levels based on genome-wide gene expression regulation. (Strayer et al., 2000; Harmer, 2009; Hsu PY et al., 2014; Takata et al., 2009; Uehara et al., 2019).Numerous studies have indicated that imperative roles for PRR gene family (PRR9, PRR7, PRR5, PRR3 and TOC1) in circadian clock (Eriksson et al., 2003; Farre et al., 2007; Fujiwara et al., 2008; Gould et al., 2006; Ito et al., 2009; Kaczorowski et al., 2003; Nakamichi et al., 2020; Salome et al., 2005; Yamamoto et al., 2003). In Arabidopsis thaliana, the gene expression and protein expression levels of PRR family members have 
54 obvious circadian rhythmic expression pattern (Matsushika et al., 2000). PRR proteins contain two domains, the N-terminal contains a conserved PR (Pseudo reciever) domain, the C-terminus is a CCT domain, and CCT domain might interact with CONSTITUITIVE PHOTOMOR-PHOGENIC 1 (COP1) to control CONSTANS (CO) protein stability, and confer CO the ability to directly bind to DNA (Makino et al., 2000; Jang et al., 2008). PRRs could interact with $\mathrm{CO}$ at specific times and stabilize $\mathrm{CO}$ expression during the day, which promoting the CO protein to bind the promoter of FLOWERING LOCUS T $(F T)$, inducing FT expression and promoting flowering (Hayama et al., 2017; Kobayashi et al., 1999; Song et al., 2012).The CCT motif of PRRs is essential for recognizing key transcriptional factors such as CCA1 (CIRCADIAN CLOCK-ASSOCIATED 1) and LHY ( LATE ELONGATED HYPOCOTYL) to coordinate physiological processes with daily cycles (Gendron et al., 2012; Kiba et al., 2007; Nakamichi et al., 2012). Many studies showed that PRRs have role at circadian rhythmic expression levels in both transcriptional and protein levels, whether in continuous light or dark (Más et al., 2003; Strayer et al., 2000). Either in the toc1 deletion mutant or TOC1 overexpressing plants of Arabidopsis thaliana, the performance of the core oscillator has significant changes (Huang et al., 2012). Besides, PRR9, PRR7 and PRR5 could act as transcriptional repressors of CCA1 and LHY (Nakamichi et al., 2010).

At present, research mainly focuses on exploring the molecular mechanism of the photoperiod regulation pathway in Arabidopsis thaliana, and its regulation mechanism is becoming clear (Song et al., 2013; Wang et al., 2013; Wickland et al., 2015). Flowering time is an important factor affecting crop yield, thus dissection of photoperiod pathways regulating flowering time in crops and ornamental plants also becomes one of the hotspots in current researches (Brambilla et al., 2017; Nakamichi et al., 2015; Yang et al., 2020). However, molecular mechanisms of the photoperiodic control in crop flowering remain unclear. Only some studies on the cloning and functional analysis of PRR genes have been carried out in crops currently, such as rice (Oryza sativa) (Murakami et al., 2005), wheat (Triticum aestivum) (Nakahira et al., 1998; Beales et al., 2007), barley (Hordeum vulgare) (Turner et al., 2005) and soybean (Glycine max) (Liu et al., 2009).

Flowering in an appropriate period has a critical effect on the fiber yield and quality of cotton, and there were only a few studies on genes related to flowering regulation in cotton (Gossypium spp.) (Cai et al., 2017; Zhang et al., 2016). With the completion of the genome sequencing of Gossypium species (Hu et al., 2019; 
81

Huang et al., 2020; Li et al., 2015; Wang et al., 2012; Wang et al., 2018; Yuan et al., 2015; Zhang et al., 2015), the identification of new genes and the establishment of a new regulatory model would be helpful for studying the function of genes involved in cotton flowering pathways. Recently, a group also has reviewed a detailed study on other genetic bases of cotton drought tolerance (Mahmood et al., 2020).

In addition, the biological clock plays a vital role in adapting to external environmental stress, such as drought stress. In Arabidopsis, a triple mutant of prr9 prr7 prr5 confers drought stress tolerance by mediating cyclic expression of stress response genes, including DREB1/CBF (dehydration-responsive element B1/Crepeat-binding factor), which are regulated by the circadian clock (Nakamichi et al., 2009; Fowler et al., 2005). In soybeans, studies shown that drought stress affects the expression of circadian clock genes, and the expression of drought-responsive genes also has shown circadian rhythm (Gomes et al., 2014). TOC1 has been shown to directly bind to the $A B A R$ promoter region and regulate the periodic expression of $A B A R$, while $\mathrm{ABA}$ can up regulate TOC1. Therefore, TOC1 is considered to act as a molecular switch between the drought stress signaling pathway and the biological clock (Legnaioli et al., 2009).

Here, we identified 44 PRR genes from the four Gossypium species, and conducted basic bioinformatics analysis. We also investigated the expression pattern of $P R R$ family members at the transcriptional level during 24 hours. Further, we identified six $P R R$ members responded to drought stress by analyzing transcriptome data with PEG treatment along with qRT-PCR verification. This study lays a foundation for studying the molecular mechanism of cotton photoperiod regulation and also provides an insight into understanding PPRs gene function in response to drought stress in cotton.

\section{Materials \& methods}

\section{Identification of PRR gene family in Gossypium spp.}

The domain numbered PF00072 (Response receiver domain) and PF06203 (CCT domain) in the Pfam database are often found in plant light signal transduction factors (Sara et al., 2019). Firstly, genome sequence of G. hirsutum (NAU-NBI v1.1 assembly genome), G. arboretum (CRI-updated_v1 assembly genome), $G$. raimondii (JGI_v2_a2.1 assembly genome) and G. barbadense (ZJU_v1.1 assembly genome) were downloaded from the Cottongen database (www.cottongen.org), respectively. This study used the protein sequences of 5 Arabidopsis PRRs were as queries to search the four Gossypium spp. proteomes through the 
basic local alignment search tool (BLAST, v 2.10.0) with default parameters (E-value $=1 \times 10^{-3}$ ) for each identified gene (Altschul et al.,1990). PR (Response receiver domain) and CCT domains, the typical PRRs domains, were aligned and searched in HMMER 3.0 (https://www.ebi.ac.uk/Tools/hmmer/) (Jacob et al., 2007). Next, sequences were searched and verified on the Conserved Domain Database (https://www.ncbi.nlm.nih.gov/Structure/cdd/wrpsb.cgi) and SMART (http://smart.embl-heidelberg.de/) (Letunic et al., 2002). Finally, the online site ExPASy Proteomics Server (http://www.expasy.org/) and Softberry(http://linux1.softberry.com/berry.phtml?topic=protcomppl \&group=programs\&subgroup=proloc) were used to analyze the physicochemical properties of the identified cotton PRR gene family, including amino acid number, nucleotide data, molecular weight, isoelectric point prediction and subcellular localization. Chromosomal locations, duplications, and synteny analysis of PRR gene members

Chromosomal location information for $P R R$ genes was obtained from general feature format (gff) files of each cotton genomic databases and genes were mapped on the chromosomes using TBtools (Chen et al., 2020).

Then MCScanX (Wang et al., 2012) was used to determine and analyze cotton PRR duplication and collinearity, Circos (http://circos.ca/) software were used to conducted image showing gene location and gene homology relationship.

\section{Phylogenetic analyses and gene structure organization of the PRR proteins in Gossypium spp.}

To analyze evolutionary relationship, the PRR proteins sequence of various plant species including Arabidopsis thaliana (Initiative et al., 2000), Cocoa (Theobroma cacao) (Argout et al., 2011) and rice (Oryza sativa) (Yu et al., 2005) were downloaded from the Arabidopsis database TAIR10

(https://www.arabidopsis.org/), the plant genome database Phytozome 12

(http://phytozome.jgi.doe.gov/pz/portal.html) and EnsemblPlants (http://plants.ensembl.org/index.html), respectively. Multi-protein sequence alignment of the PRR proteins were aligned using MEGA7.0 (Sudhir et al., 2016), and constructed a phylogenetic tree using neighbor-joining (NJ) method with the bootstrap 1000.

Finally, the evolutionary tree is visualized and beautified by the online software iTOL (https://itol.embl.de/)

(Letunic et al., 2019).Location information of PRR members were obtained from gff files using SeqHunter1.0 (Ye et al., 2010) and the gene structures were displayed by the online software Gene Structure Display Server (GSDS 2.0) (http://gsds.cbi.pku.edu.cn/index.php) (Guo et al., 2007), and we performed motifs analysis on the 
135

136

137

online software MEME (http://meme-suite.org/) (Bailey et al., 2009) with following parameters: the maximum number discovered for the motif is 10 , and the other parameters are default values. The graphic display is based on the Amazing optional gene viewer section in the software TBtools.

To identify the cis-elements in the promoter sequences of the 16 PRR family genes in G. hirsutum, the 2000 bp of genomic sequences upstream of the start codon for each $P R R$ gene were submitted to the online site PlantCARE (http://bioinformatics.psb.ugent.be/webtools/plantcare/html/), and the results are displayed by the Simple Bio Sequence Viewer in TBtools.

\section{Plant materials and treatment}

The upland cotton (G. hirsutum) accession (Lumianyan 19, LMY 19) (Li et al., 2004), an early maturing variety, selected in this study were kept in our laboratory, planted in growth chamber (day/night temperature cycle of $28^{\circ} \mathrm{C}$ light $/ 25^{\circ} \mathrm{C}$ dark with a 12 -photoperiod), and samples were picked every $3 \mathrm{~h}$ from leaf in threetrue-leaves stage. Germinated TM-1 cotton seeds were planted in the same photoperiod and temperature environment as LMY19, and treated with $400 \mathrm{mM}$ polyethylene glycol (PEG6000) at the three-leaf stage from 7 am. TM-1 seedlings were divided into four treatment groups, treated with PEG for $0,1,3$ and $6 \mathrm{~h}$, respectively, and non-PEG treated seedling (treated with sterilized water) as control check at the same time point. Then we collected leaf samples at $0 \mathrm{~h}, 1 \mathrm{~h}, 3 \mathrm{~h}$ and $6 \mathrm{~h}$ after PEG treatment and non-PEG treated samples at each of the time point. Three biological replicates for each sample, the leaves from three seedlings as a biological replicate, and all samples were freezed with liquid nitrogen immediately and stored at $-80{ }^{\circ} \mathrm{C}$ for qRT-PCR.

\section{RNA isolation and $q R T-P C R$ analysis}

The RNA was extracted from the samples using the Rapid Universal Plant RNA Extraction Kit (Huayueyang Biotechnology Co. Ltd.), and the Prime Scrip First Strand cDNA Synthesis Kit (Takara) used for reverse transcription, SYBR Premix Ex Taq II. (Takara) kit used for real-time PCR experiment, qRT-PCR analysis was carried out using SYBR Green on the Roche LightCycler ${ }^{\circledR} 480$ II. The primers of PRR gene family were designed using Primer Premier 5.0 software and listed in table S1, and the actin gene (AF059484) was selected as the internal reference gene (Zhang et al., 2013). The volume of the qRT-PCR reaction was $20 \mu \mathrm{L}$, and the amplification procedure was as follows: pre-denaturation at $95^{\circ} \mathrm{C}$ for $30 \mathrm{~s}$; denaturation at $95{ }^{\circ} \mathrm{C}$ for $5 \mathrm{~s}$, 
162

163

annealing at $60^{\circ} \mathrm{C}$ for $30 \mathrm{~s}, 40$ cycles. Three biological and technical replicates were performed for the qRTPCR tests. The relative gene expression levels were quantified by the $2^{-\Delta \Delta \mathrm{Ct}}$ method (Livak et al., 2001).

\section{Expression patterns and pathway enrichment analysis of PRR members}

RNA-Seq data of G. hirsutum TM-1were obtained from the SRA database (PRJNA248163) (Zhang et al., 2015), and the FPKM (fragments per kilobase per million reads) values were calculated by RNA-seq data downloaded from the database of cottonFGD (https://cottonfgd.org/)(Zhu et al., 2017). The gene expression pattern of $P R R$ genes were displayed by $\mathrm{R} /$ pheatmap with the expression values normalized by $\log _{2}(\mathrm{FPKM}+1)$. The expression profiles of all 16 GhPRR genes at different time of PEG treatment were further analyzed using R/Mfuzz. The differentially expressed genes (DEGs) were identified by DEseq2 (Anders et al., 2010). All detected genes in each sample were used to identify significantly DEGs $(\mid \log 2$ Foldchange $\mid>1, \mathrm{P}<0.05)$ and KEGG analyses of DEGs were conducted in the Kyoto Encyclopedia of Genes and Genomes (KEGG) database for enrichment (Kanehisa et al., 2014), KEGG enrichment of DEGs was evaluated with KOBAS2.0 software (Xie et al., 2011) and bubble graph was displayed by R/ggplot2.

\section{Results}

\section{Genome-wide identification of PRR family genes in Gossypium spp.}

Based on multiple sequence alignment analysis, complete $P R R$ genes were identified in four Gossypium species, including 16 in $G$. hirsutum $\left(\mathrm{AD}_{1}\right), 9$ in $G$. arboretum $\left(\mathrm{A}_{2}\right), 10$ in $G$. raimondii $\left(\mathrm{D}_{5}\right)$, and 9 in $G$. barbadense $\left(\mathrm{AD}_{2}\right)$. Additionally, we proceeded with $P R R$ genes retrieved from plant genome database, with 5 in Arabidopsis (dicots), 5 in rice (monocots), and 6 in cocoa (dicot). All of them were renamed based on the homologous genes in Arabidopsis (Table S2). The number of $P R R$ gene family in G. hirsutum (AtDt) was about twice as that in G. arboreum (A group) or G. raimondii (D group), it is consistent with the former one being tetraploid and the latter two being diploid. The basic information of $P R R$ genes including protein sequence length, isoelectric points, and molecular weight in cotton were listed in Table S3. The predicted GhPRR proteins ranged from 552 (GhPRR1a and GhPRR1b) to 795 (GhPRR3a) amino acids, with isoelectric points changed from 4.97 (GhPRR9a) to 8.42 (GhPRR3d) and molecular weight from $61.87 \mathrm{kDa}$ (GhPRR1a) to $85.93 \mathrm{kDa}(\mathrm{GhPRR} 3 \mathrm{a})$.

Chromosomal locations, duplications, and synteny analysis of PRR gene members 
189 In order to display the chromosome distribution of $P R R$ genes, mapping them on the corresponding

190

191

192

193

194

chromosome. Eight of GhPRR genes were located on chromosomes of At sub-genome while five of GhPRR genes were on that of Dt sub-genome and three GhPRR genes were present in different scaffolds (Fig.S1). We further conducted whole genome collinearity analysis of 44 identified $P R R$ genes in cotton, and explored the locus relationships between At and Dt sub-genomes as well as with A and D diploid cotton genomes (Fig.1A, Table S4). There are 34 orthologous gene pairs were resulted from whole genome duplication or segmental duplication among Gossypium spp. Whole Genome duplication or segmental duplication was suggested to be the main causes of PRR gene family expansion in cotton (Table S5).

\section{Phylogenetic analyses and gene structure organization of the PRR proteins in Gossypium spp.}

To investigate the evolutionary relationship of GhPRR proteins among mentioned seven species, phylogenetic tree was constructed (Fig.1B). The PRR family of Gossypium was divided into 5 subgroups (clade I-V). There were 13 PRRs in Clade III (three GaPRRs, GbPRRs and GrPRRs respectively, four GhPRRs) and 11 PRRs (one GrPRR, two GaPRRs, four GbPRRs and GhPRRs individually) in clade IV. Clade I consisted of 9 PRRs (one GaPRR, two GbPRRs and GhPRRs singly, four GrPRRs), Clade V contained 7 PRRs (one GrPRR, two GaPRRs and four GhPRRs) and Clade II had 4 PRRs (one GaPRR and GrPRR respectively, two GhPRRs). GhPRRs were distributed throughout five subgroups (clade I-V), clade-I, clade-II and clade-IV containing PRRs from monocots and dicots simultaneously, illustrating that evolution of GhPRR genes in three clades occurred before the separation of monocots and dicots.

PRRs protein in G. hirsutum was also divided into five subgroups (Fig. 2A), consistent with phylogenetic analyses. The motif distribution indicated that the order, size, and location of the motifs in the same subgroup were similar, but there were significant variety between different subgroups. Among them, $37.5 \%$ of the family members have the same sequence of motif structure: motif 4_9_3_1_7_5_6_10_8_2, while Clade-I contains the least number of motifs with only 5 motifs. All members of the PRR gene family contain motif1, motif2, motif3, motif4 and motif6, which are the conserved motifs of PRR family. In addition, the gene structure analysis exhibited that the distribution of introns and exons were similar among different subgroups, and the functional elements PR and CCT were distributed in both end side of each gene (Fig. 2B). All of member contained three PR structure elements, and most member contain two CCT domains, except that two members

Peer] reviewing PDF | (2020:05:48802:2:0:NEW 18 Aug 2020) 
216

217

218

219

220

221

222

223

224

225

226

227

228

229

230

231

232

233

234

235

236

237

238

239

240

241

242

of the Clade-I subgroup contain one CCT domain.

To further analyze the transcriptional regulation and potential function of the $P R R$ genes, the cis-elements in the promoter region were predicted (Fig. 2C). The results displayed that there are abundant regulatory elements existing in the promoter region, mainly focused on light response elements (G-Box, GT1-motif and TCT-motif, etc.), hormone responsive elements: abscisic acid response (ABRE), MeJA-response (CGTCA-motif and TGACG-motif), gibberellin-responsive element (TATC-box, P-box and GARE-motif), and stress responsive elements: drought-inducibility (MBS), low-temperature response (LTR), etc. There are 16, 14 and $6 P R R$ genes containing response elements to light, abscisic acid and drought stress, respectively. Motif sequences are often the binding sites of some sequence-specific proteins (such as transcription factors), have important biological significance for important biological processes, such as RNA initiation, RNA termination, RNA cleavage, etc.

\section{The expression pattern of PRR members under diurnal changes}

A feature shared by many clock gene transcripts is that their abundance is subject to diurnal oscillation. To analyze the peak transcripts of GhPRRs under diurnal cycle, the relative expression levels of GhPRRs together with its related genes (GhFT (FLOWERING LOCUS T), GhCO (CONSTANS LIKE -2), GhLHY (LATE ELONGATED HYPOCOTYL) and GhCCA1 (CIRCADIAN CLOCK-ASSOCIATED 1)) during 24 hours was detected by qRT-PCR (Fig. 3 and Table S6). The results showed that GhLHY-mRNA began to accumulate after dawn, and then mRNA of GhPRR genes began to reach the peak sequentially within a 24-hour period with multiple members at each peak. GhFT, GhCO, and $G h L H Y$ had the peak expression at 3 hours after light. Subsequently, members inclade-II (GhPRR9a and GhPRR9b) and clade-IV (GhPRR7a, GhPRR7b, GhPRR7c and $G h P R R 7 d$ ) reached the expression peak after 6 hour of light condition, and then members in clade III (GhPRR5a, GhPRR5b, GhPRR5c and GhPRR5d) and clade-V (GhPRR3a and GhPRR3c) at 9 hour, another two members of clade-V (GhPRR3b and GhPRR3d) at 12 hour. Finally, members (GhPRR1a and GhPRR1b) in clade-I reached expression peak after 3 hour of dark. Additionally, the expression of GhLHY and GhPRR $1 b$ always showed an opposite trend during 24 hours, it can be speculated that a mutual inhibition maybe exist between the two genes. These results indicated that expression of GhPRR genes has obvious rhythmic expression trend waves during 24 hours. 
243

244

245

246

247

248

249

250

251

252

253

254

255

256

257

258

259

260

261

262

263

264

265

266

267

268

269

\section{Identification of drought-stress related PRR genes in G. hirsutum}

To investigate the roles for PRR genes in response to drought, we investigated the expression profile of GhPRRs under polyethylene glycol (PEG) treatment at 1,3 and $6 \mathrm{~h}$ from the published transcriptome data sets. All detected genes in each sample were used to identify significantly DEGs $(\mid \log 2$ Foldchange $\mid>1, \mathrm{P}<0.05)$ among PEG_1h vs CK, PEG_3h vs CK, PEG_6h vs CK groups, and the PEG_6h group contains the most number of DEGs (Table S7), so we selected the group data at $6 \mathrm{~h}$ treated with PEG for KEGG (Kyoto Encyclopedia of Genes and Genomes) analysis (Fig.4A).The results revealed that the DEGs are mainly involved in circadian rhythm, photosynthesis, starch and sucrose metabolism, etc. (Fig.4B). Six of GhPRR genes including three members in clade III (GhPRR5a, b, $d)$ and two in clade-V (GhPRR3a and GhPRR3c) were involved in circadian rhythm pathway. The expression patterns of these GhPRR genes have high expression level at $6 \mathrm{~h}$ with PEG treatment (Fig. 4C and Table S8), further analyzed and divided into 3 clusters, three members of clade III (GhPRR5a-d) and two of clade-V (GhPRR3a and GhPRR3c) in Cluster1 exhibited the same expression trend (Fig. S2 and Table S9), suggesting these $P R R$ genes are significantly induced by PEG treatment. .

To further prove the expression changes of these genes at different time of PEG treatment $(0 \mathrm{~h}, 1 \mathrm{~h}, 3 \mathrm{~h}$ and $6 \mathrm{~h}$ ), the expression level of all member of PRR family were detected by qRT-PCR (Fig. 5A-P and Table S10). The expression of genes (GhPRR3a, $c$ and GhPRR5a, b, d) at the sixth hour after PEG6000 treatment was significantly higher than that of the blank control. All PRR genes displayed almost the similar expression changes compared with transcriptome data sets $(\mathrm{CK}, 1 \mathrm{~h}, 3 \mathrm{~h}, 6 \mathrm{~h})$, and the correlation analysis between the transcriptome and qRT-PCR of GhPRR genes displayed by scatter plots, the result showed that the Pearson correlation coefficient $\log 2$ expression ratios calculated from qRT-PCR and RNA-seq of GhPRR genes was 0.78 (Fig. S3), suggesting the results are credible. It can be considered that genes mentioned above (GhPRR3a, $c$ and GhPRR5a, $b, d$ ) maybe respond to drought stress.

\section{Discussion}

Light, one of the vital environmental factors, plays a significant role in promoting plant growth and development. Especially, with the alternating of sunrise and sunset, plants form a unique biological clock to regulate the growth and metabolic activities, like regulation of flowering time (Hayama et al., 2017; Song et al., 
270

271 272 2009), and so on.

273

274

275

276

277

278

279

280

281

282

283

284

285

286

287

288

289

290

291

292

293

294

295

296

2015), hypocotyl elongation (Seaton et al., 2015; Soy et al., 2016; Zhu et al., 2016), biotic (Bhardwaj et al., 2011; Korneli et al., 2014; Zhang et al., 2013) and abiotic stress response (Keily et al., 2013; Nakamichi et al.,

Advances in cotton genomics and genetics recent years allowed us to perform a systematic study on $P R R$ genes and to probe their potential functions in circadian clock. Here, sixteen $G h P R R$ genes were identified totally in G. hirsutum, and phylogenetic tree were constructed to show the evolutionary relationship of PRR proteins in G. hirsutum and other plant species (Fig.1B). The PRR family of Gossypium was divided into 5 subgroups (Clade I-V), which consistent that of in Arabidopsis (PRR1 (TOC1), PRR3, PRR5, PRR7, PRR9). Orthologue genes always share identical biological functions over evolutionary stages (Altenhoff et al., 2009), the exon-intron structure and the motif distribution of GhPRR genes in the same subgroup were similar. According to chromosomal localization and genomic collinearity analysis, it can be speculated that due to the hybridization of A and D subgenome in the G. hirsutum, the gene amplification is carried out by tandem repeat and fragment replication (Jackson et al., 2010).There is a high degree of collinearity between the $P R R$ genes of the At and the Dt subgenome of the tetraploid G. hirsutum (Li et al., 2015). In this study, 14 (7 pairs) of 16 PRR members are orthologous genes, indicating that $G$. hirsutum has undergone large-scale gene rearrangement at the genomic level during species formation, which is consistent with the results of the allotetraploid G. hirsutum genome (Wang et al., 2018; Li et al., 2015; Zhang et al., 2015).

A large number of experimental studies have been carried out about circadian clock in Arabidopsis (Alabadi et al., 2001; Más et al., 2003; Legnaioli et al., 2009). PRRs proteins interact with CCA1 and LHY through complex mechanisms, playing a vital role in the growth and development, flowering induction and metabolic regulation of plants (Harmer, 2009; Legnaioli et al., 2009; Mizuno et al., 2005). The function of some circadian clock-related genes has been cloned and verified based on gene homology in major crops, such as rice, soybean (Gome et al., 2014; Xue et al., 2012; Yang et al., 2013). So far, circadian clock regulation mechanism in cotton is still a mystery, only one study has identified $G h \_D 03 G 0885(G h P R R 1 b)$ as a candidate gene for cotton early maturity traits using genotyping-by-sequencing (Li et al., 2017). TOC1 (known as Pseudo Response Regulator, PRR1) is an important component of the core oscillator and closed positive and negative feedback loop with LHY (Late Elongated Hypocotyl) and CCA1 (Circadian Clock Associated 1), formulating 
297 the basic framework of the Arabidopsis circadian clock core oscillator (Alabadi et al., 2001; Gendron et al., 298 2012; Huang et al., 2012).

299 Further, qRT-PCR analysis revealed that the relative expression of PRR members had apparent rhythmic

300

301

302

303

304

305

306

307

308

309

310

311

312

313

314 expression trend among 24 hours, which similar with that of PRR members (PRR1/TOC1, PRR3, PRR5, PRR7, PRR9) in Arabidopsis. Transcript expression peaks appear in the order of PRR9, PRR7, PRR5, PRR3 and TOC1 (PRR1) in Arabidopsis (Matsushika et al., 2000), while four expression peaks appeared in this study and there were multiple members at each peak, speculating that it is related to chromosome doubling in the process of forming allotetraploid in G. hirsutum (Jackson et al., 2010). The PRRla gene had the last peak of expression and highly expressed at night, which consistent with that of APRR1 in Arabidopsis (Caluwé et al., 2016), while GhPRR1b has two peak of expression at night in this study. Therefore, detailed study should be carried out about this the gene in cotton.

In cotton, $G h L H Y$-mRNA began to accumulate after dawn, and then members of the GhPRR gene family began to reach the peak sequentially within a 24-hour period, which is consistent with the results in Arabidopsis. The GhPRR1b gene has high homology with PRR1 in Arabidopsis thaliana by alignment, so it is speculated that GhPRRIb is the core component of the circadian clock in G. hirsutum. GhPRR $1 b$ and GhLHY have opposite expression trends among 24 hours, and there may be a mutual inhibition between $G h P R R 1$ and GhLHY, the expression trends of which consistent with PRR1 gene in Arabidopsis thaliana. As an inhibitor of circadian clock gene expression, TOC1 gene can inhibit the expression of most circadian clock core genes, and affect flowering pathway of photoperiod regulation by controlling the function of circadian clock (Strayer et al., 2000; Pokhilko et al., 2012).. As an important factor in the export pathway of the circadian clock, CO protein has been proved in Arabidopsis to confirm the stability of PRRs protein-mediated CO expression, and can enhance the binding of CO to FT promoter, then FT start transcribe and promote flowering (Jang et al., 2008). The pathway of PRRs family members mediate the stability of CO expression still needs further experiments in cotton.

In addition, there are many studies focus on the response of circadian clock to abiotic stress in crops (Flowers et al., 2004; Lu et al., 2017; Zhang et al., 2020). TOC1 can bind to the ABAR promoter of ABArelated genes and regulate its circadian rhythm expression, and can be thought to act as molecular switches 
324 between drought stress signaling pathways and circadian clocks in Arabidopsis (Legnaioli et al., 2009). In

325

326

327

328

329

330

331

332

333

334

335

336

337

338

339

340

341

342

343

344

345

346

347

348

349

soybeans, studies have also shown that drought stress affects the expression of circadian clock genes, and the expression of drought-responsive genes also has circadian rhythm (Gomes et al., 2014). Based on these researches, this study identified 16 PRR members in cotton and analyzed the expression pattern of PRR genes during 24 hours and in response to drought stress. The result showed that PRR members' expression display obvious rhythmic expression trend and six of them may be involved in responding to drought stress, which is helpful to understand the evolution and function of the PRRs gene family, and provide thoughts and clues for further study the function of the PRR gene family in cotton.

\section{Conclusions}

In this study, we identified $44 P R R$ genes in cotton (Gossypium spp.) and classified them into 5 subgroups based on the phylogenetic tree. Then we comprehensively and systematically analyzed PRRs in cotton (Gossypium spp.), including the domains, the gene structure, promoter cis-acting element, chromosome localization distribution and collinearity analysis. In addition, we also investigated the evolutionary relationship of PRRs among G. hirsutum, G. barbadense, G. arboreum and G. raimondii, Arabidopsis thaliana, Theobroma cacao and Oryza sativa. Moreover, qRT-PCR results showed that the expression of members of PRRs family has obvious rhythmic expression trend, and gene differential expression and KEGG enrichment analysis of the transcriptome data with PEG treatment, along with qRT-PCR verification altogether demonstrated members of clade III $(G h P R R 5 a, b, d)$ and two members of clade-V (GhPRR3a and GhPRR3c) are significantly induced by PEG treatment, so it is speculated that these GhPRR genes may be involved in drought response. This study will provide a theoretical basis for studying the function of PRRs in cotton.

\section{Availability of data and materials}

All related data are available within the manuscript and its additional files. The RNA sequences raw data was downloaded from the SRA database, National Center for Biotechnology Information (NCBI) under the accession numbers (PRJNA248163).

\section{Funding}

This work is supported by the National Science Foundation in China (31671742); the National Project of 
350 Modern Agricultural Industry Technology System in China [CARS-15-05]; the Taishan Scholars Program of

351 Shandong Province [ts201511070].

\section{Acknowledgements}

353 The authors thank Guoyong Fu and Tahir Mahmood for kindly revising this manuscript.

\section{Conflict of Interest}

355 The authors declare that they have no conflict of interest.

356 
357

358

359

360

361

362

363

364

365

366

367

368

369

370

371

372

373

374

375

376

377

378

379

380

381

382

383

384

385

386

387

388

389

390

391

392

393

394

395

396

397

\section{Reference}

Alabadí D, Oyama T, Yanovsky MJ, Harmon FG, Más P, Kay SA. 2001. Reciprocal regulation between TOC1 and LHY/CCA1 within the Arabidopsis circadian clock. Science 293:880-883 DOI 10.1126/science.1061320.

Altenhoff AM, Dessimoz C. 2009.Phylogenetic and functional fssessment of orthologs inference projects and methods. PLoS Computational Biology 5: e1000262.DOI 10.1371/journal.pcbi.1000262

Altschul SF, Gish W, Miller W, Myers EW, Lipman DJ. 1990. Basic local alignment search tool (BLAST). Journal of molecular biology 215:403-410.DOI 10.1016/S0022-2836(05)80360-2

Anders, S., Huber, W. 2010. Differential expression analysis for sequence count data. Genome Biology 11, R106. DOI https://doi.org/10.1186/gb-2010-11-10-r106.

Argout X, Salse J, Aury JM, Guiltinan MJ, Droc G, Gouzy J, Allegre M, Chaparro C, Legavre T, Maximova SN, Abrouk M, Murat F, Fouet O, Poulain J, Ruiz M, Roguet Y, Rodier-Goud M, Barbosa-Neto JF, Sabot F, Kudrna D, Ammiraju JS, Schuster SC, Carlson JE, Sallet E, Schiex T, Dievart A, Kramer M, Gelley L, Shi Z, Bérard A, Viot C, Boccara M, Risterucci AM, Guignon V, Sabau X, Axtell MJ, Ma Z, Zhang Y, Brown S, Bourge M, Golser W, Song X, Clement D, Rivallan R, Tahi M, Akaza JM, Pitollat B, Gramacho K, D'Hont A, Brunel D, Infante D, Kebe I, Costet P, Wing R, McCombie WR, Guiderdoni E, Quetier F, Panaud O, Wincker P, Bocs S, Lanaud C. 2011. The genome of Theobroma cacao. Nature Genetics 43:101-108 DOI 10.1038/ng.736.

Bailey TL, Boden M, Buske FA, Frith M, Grant CE, Clementi L, Ren JY, Li WW, Noble WS. 2009. MEME Suite: tools for motif discovery and searching. Nucleic Acids Research 37:202 DOI 10.1093/nar/gkp335.

Beales J, Turner A, Griffiths S, Snape JW, Laurie DA.2007. A Pseudo-Response Regulator is misexpressed in the photoperiod insensitive Ppd-D1a mutant of wheat (Triticum aestivum L.). Theoretical \& Applied Genetics 115:721-733.DOI 10.1007/s00122-007-0603-4.

Bhardwaj V, Meier S, Petersen LN, Ingle RA, Roden LC. 2011. Defence responses of Arabidopsis thaliana to infection by Pseudomonas syringae are regulated by the circadian clock. PLoS ONE 6: e26968 DOI 10.1371/journal.pone.0026968.

Brambilla V, Gomez-Ariza J, Cerise M, Fornara F. 2017. The importance of being on time: regula tory networks controlling photoperiodic flowering in cereals. Frontiers in Plant Science 8:665 DOI 10.3389/fpls.2017.00665.

Cai D, Liu H, Sang N, Huang X. 2017.Identification and characterization of CONSTANS-like (COL) gene family in upland cotton (Gossypium hirsutum L.). PLoS ONE 12:e0179038 DOI 10.1371/journal.pone.0179038.

Chen CJ, Chen H, Zhang Y, Thomas HR, Frank MH, He YH, Xia R. 2020. TBtools - an integra tive toolkit developed for interactive analyses of big biological data. Molecular Plant DOI https://doi.org/10.1016/j.molp.2020.06.009.

De Caluwé J, Xiao Q, Hermans C, Verbruggen N, Leloup JC, Gonze D. 2016. A compact model for the complex plant circadian clock. Frontiers in Plant Science 7:74 DOI 10.3389/fpls.2016.00074.

Du XM, Huang G, He SP, Yang ZE, Sun GF, Ma XF, Li N, Zhang XY, Sun JL, Liu M, Jia YH, Pan ZE, Gong WF, Liu ZH, Zhu HQ, Ma L, Liu FY, Yang DG, Wang F, Fan W, Gong Q, Peng Z, Wang LR, 
Wang XY, Xu SJ, Shang HH, Lu CR, Zheng HK, Huang SW, Lin T, Zhu YX, Li FG. 2018.

Resequencing of 243 diploid cotton accessions based on an updated A genome identifies the genetic basis of key agronomic traits. Nature Genetics 50:796-802

DOI 10.1038/s41588-018-0116-x.

Eriksson ME, Hanano S, Southern MM, Hall A, Millar, AJ. 2003. Response regulator homologues have complementary, light dependent functions in the Arabidopsis circadian clock. Planta 218:159-162 DOI 10.1007/s00425-003-1106-4.

Farre EM, Kay SA. 2007. PRR7 protein levels are regulated by light and the circadian clock in Ara bidopsis. Plant Journal 52:548-560.DOI 10.1111/j.1365-313x.2007.03258.x.

Flowers TJ. 2004. Improving crop salt tolerance. Journal of experimental botany 55:307-319 DOI $10.1093 / \mathrm{j} x \mathrm{~b} / \mathrm{erh} 003$.

Fowler SG, Cook D, Thomashow MF. 2005. Low temperature induction of Arabidopsis CBF1, 2, and 3 is gated by the circadian clock. Plant Physiology 137: 961-968.

DOI 10.1104/pp.104.058354.

Fujiwara S, Wang L, Han L, Suh S, Salome PA, Mcclung CR, Somers DE.2008. Post-translational Regulation of the Arabidopsis Circadian Clock through Selective Proteolysis and Phosphorylation of Pseudo-response Regulator Proteins. Journal of Biological Chemistry 283: 23073-23083. DOI 10.1074/jbc.M803471200.

Gendron JM, Pruneda-Paz JL, Doherty CJ, Gross AM, Kang SE, Kay SA. 2012. Arabidopsis circadian clock protein, TOC1, is a DNA-binding transcription factor. Proceedings of the National Academy of Sciences of the United States of America 109:3167-3172

DOI 10.1073/pnas.1200355109.

Gome JM, Rodrigues FA, Pagliarini RF, Bendix C, Nakayama TJ, Celaya B, Molinari HBC, Oliveira MCN, Harmon FG, Nepomuceno A. 2014. Diurnal oscillations of soybean circadian clock and drought responsive genes. PLOS ONE 9:e86402 DOI 10.1371/journal.pone.0086402.

Gould PD, Locke JCW, Larue C, Southern MM, Davis SJ, Hanano S, Moyle R, Milich R, Putterill J, Millar AJ, Hall A. 2006. The molecular basis of temperature compensation in the Arabidopsis circadian clock. The Plant Cell 18:1177-1187 DOI 10.1105/tpc.105.039990.

Guo AY, Zhu QH, Chen X, Luo JC. 2007. GSDS: A gene structure display server. Hereditas 29:1023-1026 DOI 10.1360/yc-007-1023.

Harmer SL. 2009. The circadian system in higher plants. Annual Review of Plant Biology 60:357-377 DOI 10.1146/annurev.arplant.043008.092054.

Hayama R, Krebs LS, Richter R, Fernández V, Jang S, Coupland G. 2017. Pseudo response reg- ulators stabilize CONSTANS protein to promote flowering in response to day length. The EMBO Journal 36:904918 DOI 10.15252/embj.201693907.

Hsu PY, Harmer SL.2014. Wheels within wheels: the plant circadian system. Trends in Plant Science 19:240249 DOI 10.1016/j.tplants.2013.11.007.

Hu Y, Chen JD, Fang L, Zhang ZY, Ma W, Niu YC, Ju LZ, Deng JQ, Zhao T, Lian JM, Baruch K, Fang DD, Liu X, Ruan YL, Rahman M, Han JL, Wang K, Wang Q, Wu HT, Mei GF, Zang YH, Han ZG, Xu CY, Shen WJ, Yang DF, Si ZF, Dai F, Zou LF, Huang F, Bai YL, Zhang YG, Brodt A, Benhamo H, Zhu XF, Zhou BL, Guan XY, Zhu SJ, Chen XY, Zhang TZ. 2019. Gossypium barbadense 
and Gossypium hirsutum genomes provide insights into the origin and evolution of allotetraploid cotton. Nature Genetics 51:739-748 DOI 10.1038/s41588-019-0371-5.

Huang G, Wu Z, Percy RG, Bai M, Li Y, Frelichowski JE, Hu J, Wang K, Yu JZ, Zhu Y.2020. Genome sequence of Gossypium herbaceum and genome updates of Gossypium arboreum and Gossypium hirsutum provide insights into cotton A-genome evolution. Nature Genetics 52:516-524 DOI 10.1038/s41588-020-0607-4.

Huang W, Pérez-García P, Pokhilko A, Millar A J, Antoshechkin I, Riechmann JL, Mas P. 2012. Mapping the core of the Arabidopsis circadian clock defines the network structure of the oscillator. Science 336:75-79 DOI 10.1126/science.1219075.

Initiative AG. 2000. Analysis of the genome sequence of the flowering plant Arabidopsis thaliana. Nature 408:796-815 DOI 10.1038/35048692.

Ito S, Kawamura H, Niwa Y, Nakamichi N, Yamashino T, Mizuno T. 2009. A genetic study of the Arabidopsis circadian clock with reference to the TIMING OF CAB EXPRESSION 1 (TOC1) gene. Plant and Cell Physiology 50:290-303 DOI 10.1093/pcp/pcn198.

Jackson S, Chen ZJ. 2010. Genomic and expression plasticity of polyploidy. Current Opinion in Plant Biology 13:153-159 DOI 10.1016/j.pbi.2009.11.004.

Jang S, Marchal V, Panigrahi KCS, Wenkel S, Soppe W, Deng XW, Valverde F, Coupland G. 2008. Arabidopsis COP1 shapes the temporal pattern of $\mathrm{CO}$ accumulation conferring a photoperiodic flowering response. The EMBO Journal 27:1277-1288 DOI 10.1038/emboj.2008.68.

Kaczorowski KA, Quail PH. 2003. Arabidopsis PSEUDORESPONSEREGULATOR7 is a signaling intermediate in phytochrome regulated seedling deetiolation and phasing of the circadian clock. Plant Cell 15:2654-2665 DOI 10.1105/tpc.015065.

Kahle D. 2013. mpoly: Multivariate Polynomials in R. The R journal 5:181-187 DOI 10.32614/RJ-2013-015.

Kanehisa M, Goto S, Sato Y, Kawashima M, Furumichi M, Tanabe M. 2014. Data, information, knowledge and principle: back to metabolism in KEGG. Nucleic Acids Research 42:199 DOI 10.1093/nar/gkt1076.

Keily J, Mac Gregor DR, Smith RW, Millar AJ, Halliday KJ, Penfield S. 2013. Model selection reveals control of cold signaling by evening-phased components of the plant circadian clock. Plant Journal 76:247257 DOI 10.1111/tpj.12303.

Kiba T, Henriques R, Sakakibara H, Chua N. 2007. Targeted degradation of PSEUDO-RESPONSE REGULATOR5 by an SCFZTL complex regulates clock function and photomorphogenesis in Arabidopsis thaliana. The Plant Cell 19: 2516-2530.DOI 10.1105/tpc.107.053033.

Kobayashi Y, Kaya H, Goto K, Iwabuchi M, Araki T.1999. A pair of related genes with antagonis tic roles in mediating flowering signals. Science 286:1960-1962

DOI 10.1126/science.286.5446.1960.

Korneli C, Danisman S, Staiger D. 2014. Differential control of pre-invasive and post-invasive anti- bacterial defense by the Arabidopsis circadian clock. Plant and Cell Physiology 55:1613-1622 DOI 10.1093/pcp/pcu092.

Lee C, Shibata Y, Rao BS, Strahl BD, Lieb JD. 2005. Plant circadian clocks increase photosynthesis, growth, survival, and competitive advantage. Science 309:630-633 DOI 10.1126/science.1115581. 
480

481

482

483

484

485

486

487

488

489

490

491

492

493

494

495

496

497

498

499

500

501

502

503

504

505

506

507

508

509

510

511

512

513

514

515

516

517

518

519

520

Legnaioli T, Cuevas J, Mas P. 2009.TOC1 functions as a molecular switch connecting the circadian clock with plant responses to drought. The EMBO Journal 28:3745-3757 DOI 10.1038/emboj.2009.297.

Letunic I, Bork P.2019. Interactive Tree Of Life (iTOL) v4: recent updates and new developments. Nucleic Acids Research 47:256 DOI 10.1093/nar/gkz239.

LetunicI, Goodstadt L, Dickens NJ, Doerks T, Schultz J,Mott R, Ciccarelli FD, Copley RR, Ponting CP, Bork P. 2002. Recent improvements to the SMART domain-based sequence annotation resource. Nucleic Acids Research 30:242-244 DOI 10.1093/nar/30.1.242.

Li F, Fan G, Lu C, Xiao G, Zou C, Kohel RJ, Ma Z, Shang H, Ma X, Wu J, Liang X, Huang G, Percy RG, Liu K, Yang W, Chen W, Du X, Shi C, Yuan Y, Ye W, Liu X, Zhang X, Liu W, Wei H, Wei S, Huang G, Zhang X, Zhu S, Zhang H, Sun F, Wang X, Liang J, Wang J, He Q, Huang L, Wang J, Cui J, Song G, Wang K, Xu X, Yu JZ, Zhu Y, Yu S. 2015. Genome sequence of cultivated Upland cotton (Gossypium hirsutum TM-1) provides insights into genome evolution. Nature Biotechnology 33:524-530 DOI 10.1038/nbt.3208.

Li L, Zhao S, Su J, Fan S, Pang C, Wei H, Wang H, Gu L, Zhang C, Liu G, Yu D, Liu Q, Zhang X, Yu S. 2017. High-density genetic linkage map construction by F2 populations and QTL analysis of early-maturity traits in upland cotton (Gossypium hirsutum L.). PLoS ONE 12:e182918

DOI 10.1371/journal.pone.0182918.

Li RZ, Wang ZW, Wang JH, Shen GF, Ge FZ. 2004. Early-maturing short-season cotton resistant to insects -- lumianyan19. China cotton 31: 17-23. DOI CNKI:SUN:ZMZZ.0.2004-04-011.

Liu H, Wang HG, Gao PF, Xü JH, Xü TD, Wang JS, Wang BL, Lin CT, Yong FF. 2009. Analy- sis of clock gene homologs using unifoliolates as target organs in soybean (Glycine max). Journal of Plant Physiology 166:278-289 DOI 10.1016/j.jplph.2008.06.003.

Livak KJ, Schmittgen TD. 2001. Analysis of relative gene expression data using real-time quantita- tive PCR and the 2(-Delta Delta C(T)) Method. Methods 25:402-408 DOI 10.1006/meth.2001.1262.

Lu TT, Zhang GF, Sun LR, Wang J, Hao FS. 2017. Genome-wide identification of CBL family and expression analysis of CBLs in response to potassium deficiency in cotton. PeerJ 5:e3653 DOI 10.7717/peerj.3653.

Mahmood T, Khalid S, Abdullah M, Ahmed Z, Shah MKN, Ghafoor A, Du XM.2020 Insights into drought stress signaling in plants and the molecular genetic basis of cotton drought tolerance. Cells $\mathbf{9}, 105$. DOI 10.3390/cells9010105.

Makino S, Kiba T, Imamura A, Hanaki N, Nakamura A, Suzuk T, Taniguchi M, Ueguchi C, Sugiyama T, Mizuno T. 2000. Genes encoding pseudo-response regulators: insight into His-to-Asp phosphorelay and circadian rhythm in Arabidopsis thaliana. Plant Cell Physiology 41:791-803. DOI 10.1093/pcp/41.6.791.

Más P, Kim WY, Somers DE, Kay KA. 2003. Targeted degradation of TOC1 by ZTL modulates circadian function in Arabidopsis thaliana. Nature 426:567-570 DOI 10.1038/nature02163.

Matsushika A, Makino S, Kojima M, Mizuno T. 2000. Circadian waves of expression of the APRR1/TOC1 family of pseudo-response regulators in Arabidopsis thaliana: insight into the plant circadian clock. Plant and Cell Physiology 41:1002-1012 DOI 10.1093/pcp/pcd043.

Mcclung CR. 2006.Plant Circadian Rhythms. The Plant Cell 18(4):792-803

Peer] reviewing PDF | (2020:05:48802:2:0:NEW 18 Aug 2020) 
DOI 10.1105/tpc.106.040980.

Mizuno T, Nakamichi N. 2005. Pseudo-Response Regulators (PRRs) or True Oscillator Components (TOCs), Plant and Cell Physiology 46:677-685 DOI 10.1093/pcp/pci087.

Murakami M, Matsushika A, Ashikari M, Yamashino T, Mizuno T. 2005. Circadian-associated rice pseudo response regulators (OsPRRs): insight into the control of flowering time. Bioscience, Biotechnology, and Biochemistry 69:410-414 DOI 10.1271/bbb.69.410.

Nakahira Y, Baba K, Yoneda A, Shiina T, Toyoshima Y. 1998.Circadian-regulated transcription of the psbD light-responsive promoter (psbD LRP) in wheat chloroplasts. Plant Physiology 118:1079-1088 DOI 10.1007/978-94-011-3953-3_664.

Nakamichi N, Kusano M, Fukushima A, Kita M, Ito S, Yamashino T, Saito K, Sakakibara H, MizunoT.2009.Transcript profiling of an Arabidopsis PSEUDO RESPONSE REGULATOR arrhythmic triple mutant reveals a role for the circadian clock in cold stress response. Plant and Cell Physiology 50:447462 DOI 10.1093/pcp/pcp004.

Nakamichi N, Kiba T, Henriques R, Mizuno T, Chua NH, Sakakibara H. 2010. PSEU DO-RESPONSE REGULATORS 9, 7, and 5 are transcriptional repressors in the Arabidopsis circadian clock. Plant Cell 22:594-605 DOI 10.1105/tpc.109.072892.

Nakamichi N, Kiba T, Kamioka M, Suzuki T, Yamashino T, Higashiyama T, Sakakibara T,Mizuno T. 2012.Transcriptional repressor PRR5 directly regulates clock-output pathways. PNAS, 42:17123-17128. DOI 10.1073/pnas.1205156109.

Nakamichi N, Kudo T, Makita N, Kiba T, Kinoshita T, Sakakibara H. 2020. Flowering time con- trol in rice by introducing Arabidopsis clock-associated PSEUDO-RESPONSE REGULATOR 5. Biosci Biotechnol Biochem 84:970-979 DOI 10.1080/09168451.2020.1719822.

Nakamichi N. 2015. Adaptation to the local environment by modifications of the photoperiod re- sponse in crops. Plant and Cell Physiology 56:594-604 DOI 10.1093/pcp/pcu181.

Norihito N, Masanori K, Kanae N, Shogo I, Takafumi Y, Tsuyoshi M, Takeshi M. 2007. Ara- bidopsis clock-associated Pseudo-Response Regulators PRR9, PRR7 and PRR5 coordinately and positively regulate flowering time through the canonical CONSTANS-dependent photoperiodic pathway. Plant and Cell Physiology 48:822-832 DOI 10.1093/pcp/pcm056.

Pokhilko A, Fernández AP, Edwards KD, Southern MM, Halliday KJ, Millar AJ.2012.The clock gene circuit in Arabidopsis includes a repressilator with additional feedback loops. Molecular Systems Biology 8:574-574 DOI 10.1038/msb.2012.6.

Potter SC, Luciani A, Eddy SR, Park Y, Lopez R, Finn RD. 2018. HMMER web server: 2018 update. Nucleic Acids Research 46:200 DOI 10.1093/nar/gky448.

Salome PA, McClung CR. 2005. PSEUDO-RESPONSE REGULATOR 7 and 9 are partially redundant genes essential for the temperature responsiveness of the Arabidopsis circadian clock. Plant Cell 17:791-803 DOI 10.1105/tpc.104.029504.

Sara El, Jaina M, Alex B, Sean RE, Aurelien L, Simon CP, Matloob Q, Lorna JR, Gustavo A S, Alfredo S, Erik LS, Layla H, Lisanna P,Damiano P, Silvio CET, Robert DF. 2019. The Pfam protein families database in 2019. Nucleic Acids Research 47:427-432. DOI 10.1093/nar/gky995.

Seaton DD, Smith RW, Song YH. 2015. Linked circadian outputs control elongation growth and flowering in response to photoperiod and temperature. Molecular Systems Biology 11:776 
DOI 10.15252/msb.20145766.

Song YH, Ito S, Imaizumi T. 2013. Flowering time regulation: photoperiod and temperature-sensing in leaves. Plant Science 18:575-583 DOI 10.1016/j.tplants.2013.05.003.

Song YH, Shim JS, Kinmonth-Schultz HA, Imaizumi T. 2015. Photoperiodic flowering: time measurement mechanisms in leaves. Annual Review of Plant Biology 66:441-464 DOI 10.1146/annurev-arplant-043014-115555.

Song YH, Smith RW, To BJ, Millar AJ, Imaizumi T. 2012. FKF1 conveys timing information for CONSTANS stabilization in photoperiodic flowering. Science336: 1045-1049. DOI 10.1126/science.1219644.

Soy J, Leivar P, González-Schain N, Martín G, Diaz C, Sentandreu M, Al-Sady B, Quail PH, Monte E.2016. Molecular convergence of clock and photosensory pathways through PIF3-TOC1 interaction and co-occupancy of target promoters. Proceedings of the National Academy of Sciences of the United States of America 113:4870-4875 DOI 10.1073/pnas.1603745113.

Strayer C, Oyama T, Schultz TF, Raman R, Somers DE, Más P, Panda S, Kreps JA, Kay SA. 2000. Cloning of the Arabidopsis clock gene TOC1, an autoregulatory response regulator homolog. Science 289:768-771 DOI 10.1126/science.289.5480.768.

Sudhir K, Glen S, Koichiro T. 2016. MEGA7: Molecular evolutionary genetics analysis version 7.0 for bigger datasets. Molecular Biology and Evolution 33: 1870-1874 DOI 10.1093/molbev/msw054.

Takata N, Saito S, Saito CK, Nanjo T, Shinohara K, Uemura M. 2009. Molecular phylogeny and expression of poplar circadian clock genes, LHY1 and LHY2. New Phytologist 18:808-819 DOI 10.1111/j.1469-8137.2008.02714.x.

Turner A, Beales J, Faure S, Dunford R, Laurie D.2005. The pseudo-response regulator Ppd-H1 provides adaptation to photoperiod in Barley. Science 310:1031-1034

DOI 10.1126/science.1117619.

Uehara TN, Mizutani Y, Kuwata K, Hirota T, Sato A, Mizoi J, Takao S, Matsuo H, Suzuki T, Ito S, Saito AN, Nishiwakiohkawa T, Yamaguchishinozaki K, Yoshimura T, Kay AS, Itami K, Kinoshita T, Yamaguchi J, Nakamichi N.2019. Casein kinase 1 family regulates PRR5 and TOC1 in the Arabidopsis circadian clock. Proceedings of the National Academy of Sciences of the United States of America 116:11528-11536 DOI 10.1073/pnas.1903357116.

Wang KB,Wang ZW, Li FG, Ye WW, Wang JY, Song GL, Yue Z, Cong L, Shang HH, Zhu SL, Zou CS, Li Q, Yuan YL, Lu CR, Wei HL, Gou CY, Zheng ZQ, Yin Y, Zhang XY, Liu K, Wang B, Song C, Shi N, Kohel RJ, Percy RG, Yu JZ, Zhu YX, Wang J, Yu SX. 2012. The draft genome of a diploid cotton Gossypium raimondii. Nature Genetics 44:1098-1103

DOI 10.1038/ng.2371.

Wang L, Kim J, Somers DE. 2013. Transcriptional corepressor TOPLESS complexes with pseudo-response regulator proteins and histone deacetylases to regulate circadian transcription. Proceedings of the National Academy of Sciences of the United States of America 110(2): 761-766.

DOI 10.1073/pnas.1215010110.

Wang MJ, Tu LL, Yuan DJ, Zhu D, Shen C, Li JY, Liu FY, Pei LL, Wang PC, Zhao GN, Ye ZX, Huang H, Yan FL, Ma YZ, Zhang L, Liu M, You JQ, Yang YC, Liu ZP, Huang F, Li BQ, Qiu P, Zhang QH, Zhu LF, Jin SX, Yang XY, Min L, Li GL, Chen LL, Zheng HK, Lindsey K, Lin ZX, Udall JA, Zhang 
XL. 2018. Reference genome sequences of two cultivated allotetraploid cottons, Gossypium hirsutum and Gossypium barbadense. Nature Genetics 51:224-229 DOI 10.1038/s41588-018-0282-x.

Wang YP, Tang HB, Debarry JD, Tan X, Li JP, Wang XY, Lee TH, Jin HZ, Marler B, Guo H, Kissinger JC, Paterson AH. 2012. MCScanX: a toolkit for detection and evolutionary analysis of gene synteny and collinearity. Nucleic Acids Research 40:49 DOI 10.1093/nar/gkr1293.

Wickland DP, Hanzawa Y. 2015. The FLOWERING LOCUS T/TERMINAL FLOWER 1 gene family: functional evolution and molecular mechanisms. Molecular Plant 8:983-997 DOI 10.1016/j.molp.2015.01.007.

Xie C, Mao XZ, Huang JJ, Ding Y, Wu JM, Dong S, Kong L, Gao G, Li CY, Wei LP. 2011. KOBAS 2.0: a web server for annotation and identification of enriched pathways and diseases. Nucleic Acids Research 39:316-322 DOI 10.1093/nar/gkr483.

Xue ZG, Zhang XM, Lei CF, Chen XJ, Fu YF. 2012. Molecular cloning and functional analysis of one ZEITLUPE homolog GmZTL3 in soybean. Molecular Biology Reports 39:1411-1418 DOI 10.1007/s11033-011-0875-2.

Yamamoto Y, Sato E, Shimizu T, Nakamich N, Sato S, Kato T, Tabata S, Nagatani A, Yam- ashino T, Mizuno T. 2003.Comparative genetic studies on the APRR5 and APRR7 genes belonging to the $A P R R 1 / T O C 1$ quintet implicated in circadian rhythm, control of flowering time, and early photomorphogenesis. Plant Cell Physiology 44:1119-1130 DOI 10.1093/pcp/pcg148.

Yang CP, Tan YR, Yan BY, Gong XX, Wang D, Gao X, Zhang H, Wang P, Li SJ, Wang Y, Zhou LY, Pan YW, Liu JP. 2020. Molecular characterization of clock-associated PSEUDO-RESPONSE REGULATOR 9 gene from Oncidium 'Gower Ramsey'. Plant Growth Regulation. Suppl 1:1-11DOI 10.1007/s10725-020-00611-6.

Yang Y, Peng Q, Chen GX, Li XH, Wu CY. 2013. OsELF3 is involved in circadian clock regulation for promoting flowering under long-day conditions in rice. Molecular Plant 6:202-217 DOI $10.1093 / \mathrm{mp} / \mathrm{sss} 062$.

Ye WW, Wang YC, Dou DL. 2010. SeqHunter: a bioinformatics toolbox for local Blast and sequence analysis. China Journal of Bioinformatics 8:364-363 DOI 10.3724/SP.J.1187.2010.00953.

Yu J, Wang J, Lin W, Li SG, Li H, Zhou J, Ni PX, Dong W, Hu SN, Zeng CQ, Zhang JG, Zhang Y, Li RQ, Xu ZY, Li ST, Li XR, Zheng HK, Cong LJ, Lin L, Yin JM, Geng JN, Li GY, Shi JP, Liu J, Lv H, Li J, Wang J, Deng YJ, Ran LH, Shi XL, Wang XY, Wu QF, Li CF, Ren XY, Wang JQ, Wang XL, Li DW, Liu DY, Zhang XW, Ji ZD, Zhao WM, Sun YQ, Zhang ZP, Bao JY, Han YJ, Dong LL, Ji J, Chen P, Wu S, Liu JS, Xiao Y, Bu DB, Tan JL, Yang L, Ye C, Zhang JF, Xu JY, Zhou Y, Yu YP, Zhang B, Zhuang SL, Wei HB, Liu B, Lei M, Yu H, Li YZ, Xu H, Wei SL, He XM, Fang LJ, Zhang ZJ, Zhang YZ, Huang XG, Su ZX, Tong W, Li JH, Tong ZZ, Li SL, Ye J, Wang LS, Fang L, Lei TT, Chen C, Chen H, Xu Z, Li HH, Huang HY, Zhang F, Xu HY, Li N, Zhao CF, Li ST, Dong LJ, Huang YQ, Li L, Xi Y, Qi QH, Li WJ, Zhang B, Hu W, Zhang YL, Tian XJ, Jiao YZ, Liang XH, Jin J, Gao L, Zheng WM, Hao BL, Liu SQ, Wang W, Yuan LP, Cao ML, McDermott J, Samudrala R, Wang J, Wong GK, Yang HM. 2005. The genomes of Oryza sativa: A history of duplications. PLoS Biology 3: 38 DOI 10.1371/journal.pbio.0030038.

Yuan DJ, Tang ZH, Wang MJ, Gao WH, Tu LL, Jin X, Chen LL, He YH, Zhang L, Zhu LF, Li Y, Liang QQ, Lin ZX, Yang XY, Liu N, Jin SX, Lei Y, Ding YH, Li GL, Ruan XA, Ruan YJ, Zhang XL. 
2015.The genome sequence of Sea-Island cotton (Gossypium barbadense) provides insights into the allopolyploidization and development of superior spinnable fibre. Scientific Reports 5:17662-17687 DOI 10.1038/srep17662.

Zhang C, Xie QG, Anderson RG, Ng G, Seitz NC, Peterson T, McClung CR, McDowell JM, Kong DD, Kwak JM, Lu H. 2013. Molecular basis of crosstalk between the circadian clock and innate immunity in Arabidopsis. PLoS Pathogens 9:e1003370 DOI 10.1371/journal.ppat.1003370.

Zhang GF, Yue CM, Lu TT, Sun LR, Hao FS. 2020. Genome-wide identification and expression analysis of $N A D P H$ oxidase genes in response to $\mathrm{ABA}$ and abiotic stresses, and in fibre formation in Gossypium. PeerJ 8:e8404 DOI 10.7717/peerj.8404

Zhang P, Fan SL, Song MZ, Pang CY, Wei HL, Yu SX. 2016. Cloning and Functional Analysis of the Flowering-related Gene GhFLP1 from Upland Cotton (Gossypium hirsutum L.). Cotton Science 28: 199-207 DOI 10.11963/issn.1002-7807.201603002.

Zhang TZ, HuY, Jiang WK, Fang L, Guan XY, Chen JD, Zhang JB, Saski CA, Scheffler BE, Stelly DM, Kemp AMH, Wan Q, Liu BL, Liu CX, Wang S, Pan MQ, Wang YK, Wang DW, Ye WX, Chang LJ, Zhang WP, Song QX, Kirkbride RC, Chen XY, Dennis E, Llewellyn DJ, Peterson DG, Thaxton P, Jones DC, Wang Q, Xu XY, Zhang H, Wu HT, Zhou L, Mei GF, Chen SQ, Tian Y, Xiang D, Li XH, Ding J, Zuo QY, Tao L, Liu YC, Li J, Lin Y, Hui YY, Cao ZS, Cai CP, Zhu XF, Jiang Z, Zhou BL, Guo WZ, Li RQ, Chen ZJ. 2015. Sequencing of allotetraploid cotton (Gossypium hirsutum L. acc. TM-1) provides a resource for fiber improvement. Nature Biotechnology 33:531-537 DOI 10.1038/nbt.3207.

Zhang Y, Wang XF, Ding ZG, Ma Q, Zhang GR, Zhang SL, Li ZK, Wu Q, Zhang GY,Ma ZY. 2013. Transcriptome profiling of Gossypium barbadense inoculated with Verticillium dahliae provides a resource for cotton improvement. BMC Genomics 14:637 DOI 10.1186/1471-2164-14-637.

Zhu JY, Oh E, Wang TN, Wang ZY. 2016. TOC1-PIF4 interaction mediates the circadian gating of thermores-ponsive growth in Arabidopsis. Nature Communications 7:13692

DOI 10.1038/ncomms13692.

Zhu T, Liang CZ, Meng ZG, Sun GQ, Meng ZH, Guo SD, Zhang Rui.2017.CottonFGD: an integrated functional genomics database for cotton. BMC Plant Biology 17:101-109. DOI 10.1186/s12870-017-1039-x. 
674 Figure legends

675 Figure 1 Phylogenetic and collinearity analysis of PRR proteins in cotton.

676 (A) Gene duplication and collinearity analysis among cotton $P R R$ genes (green lines and brown indicates

677 paralogous genes in G. hirsutum and G. barbadense, orange lines indicates orthologous genes between $G$.

678 arboreum and G. hirsutum, black lines indicates orthologous genes between G. arboreum and G. raimondii,

679 blue lines indicates orthologous genes between G. barbadense and G. hirsutum, seagreen indicates orthologous

680 genes between G. arboreum and G. barbadense, lightsteelblue indicates orthologous genes between $G$.

681 barbadense and G. raimondii, yellow indicates orthologous genes between G. raimondii and G. hirsutum).

682 Gene duplication and collinearity displayed on Circos (http://circos.ca/); (B) Phylogenetic tree of the PRR gene

683 family.

684 Figure 2 Genetic structure and motif prediction of PRR members.

685 (A) Genetic structure of GhPRR genes; (B) motif prediction of GhPRR proteins (right panel); Length of each 686 motif are shown proportionally. (C) Cis-elements prediction of GhPRR promoters. The scale bar is shown at 687 the bottom.

688 Figure 3 The expression pattern of PRR gene family and related genes during 24 hours in LMY19. 689 White and black bars on X-axis indicate day and night conditions. Error bars represent means \pm standard 690 deviation $(\mathrm{n}=3)$.

691 Figure 4 Expression analysis and KEGG enrichment of $P R R$ genes.

692 (A)Differential expression genes analysis; (B) KEGG pathway enrichment of DEGs PEG_6 h group;

693 (C)Expression pattern of GhPRR genes with PEG treated at CK, 1, 3 and $6 \mathrm{~h}$. Count sizes of dots correspond to 694 numbers of genes, and their colors correspond to -log10 (p-value) of pathway enrichment. DEGs: differentially 695 expressed genes.

696 Figure 5 qRT-PCR analysis of $P R R$ genes under PEG treatment and non-PEG treatment (CK) at $0,1,3$, $6976 \mathbf{h}$. The * and **indicate significant differences at $\mathrm{p}<0.05$ and $\mathrm{p}<0.01$ level, respectively. Differences analysis 698 were compared using one-way ANOVA.

699 Supplemental Information

700 Figure S1 Distributions of the PRR family genes on chromosomes in Gossypium spp. (A) Distributions of

701 GaPRR genes on chromosomes in G. arboretum; (B) Distributions of GbPRR genes on chromosomes in $G$.

Peer) reviewing PDF | (2020:05:48802:2:0:NEW 18 Aug 2020) 
702

703

704

705

706

707

708

709

710

711

712

713

714

715

716

717

718

719

720

721 barbadense; (C) Distributions of GhPRR genes on chromosomes in G. hirsutum; (D) Distributions of GrPRR genes on chromosomes in G. raimondii. The chromosome number is shown above each chromosome. The scale bar beside the chromosome indicates the length in mega-bases $(\mathrm{Mb})$.

Figure S2 Cluster analysis of GhPRR genes with PEG treated at CK, 1 h, 3 h and 6 h.

Figure S3 Correlation analysis between the transcriptome and qRT-PCR of GhPRR genes. Scatter plots represent $\log 2$ expression ratios calculated from qRT-PCR and RNA-seq of GhPRR genes. The relative expression value from qRT-PCR; X-axis: the FPKM value from transcriptomic data sets.

Table S1 qRT-PCR primers for GhPRR and related genes used in this study.

Table S2 Rename information of $P R R$ genes and the homology information of PRR sequences between Arabidopsis and Gossypium spp.

Table S3 The general information of the PRR gene family.

Table S4 Orthologous relationships among four Gossypium species.

Table S5 The duplication of PRR gene pairs in Gossypium spp.

Table S6 The Ct value of qPCR raw data in Fig.3. Rep-1, 2, 3 refers biological replicate, respectively.

Table S7 The DEGs together with their detail information of PEG_1h vs CK, PEG_3h vs CK, PEG_6h vs CK.

Table S8 The FPKM value of GhPRR genes with PEG treated at 0, 1, 3 and 6 h.

Table S9 Details of GhPRR cluster analysis.

Table S10 The Ct value of qPCR raw data in Fig.5. Rep-1, 2, 3 refers biological replicate, respectively. 
Figure 1

Phylogenetic and collinearity analysis of PRR proteins in cotton.

(A) Gene duplication and collinearity analysis among cotton PRR genes (green lines and brown indicates paralogous genes in G. hirsutum and G. barbadense, orange lines indicates orthologous genes between G. arboreum and G. hirsutum, black lines indicates orthologous genes between $G$. arboreum and G. raimondii, blue lines indicates orthologous genes between $G$. barbadense and $G$. hirsutum, seagreen indicates orthologous genes between $G$. arboreum and G. barbadense, lightsteelblue indicates orthologous genes between $G$. barbadense and G. raimondii, yellow indicates orthologous genes between G. raimondii and G. hirsutum). Gene duplication and collinearity displayed on Circos (http://circos.ca/); (B) Phylogenetic tree of the $P R R$ gene family.
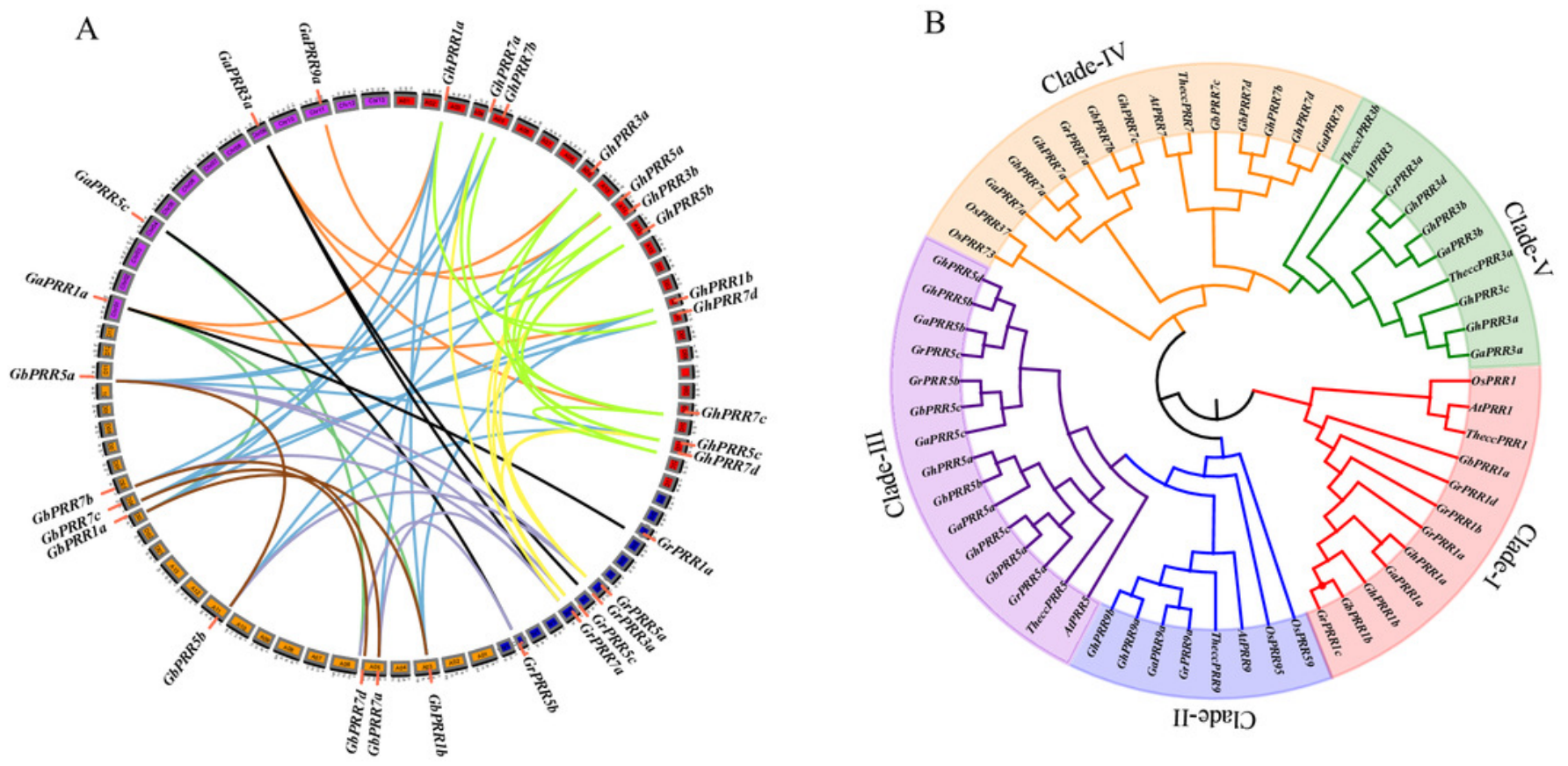
Figure 2

Genetic structure and motif prediction of PRR members.

(A) Genetic structure of GhPRR genes; (B) motif prediction of GhPRR proteins (right panel); Length of each motif are shown proportionally. (C) Cis-elements prediction of GhPRR promoters. The scale bar is shown at the bottom. 
A

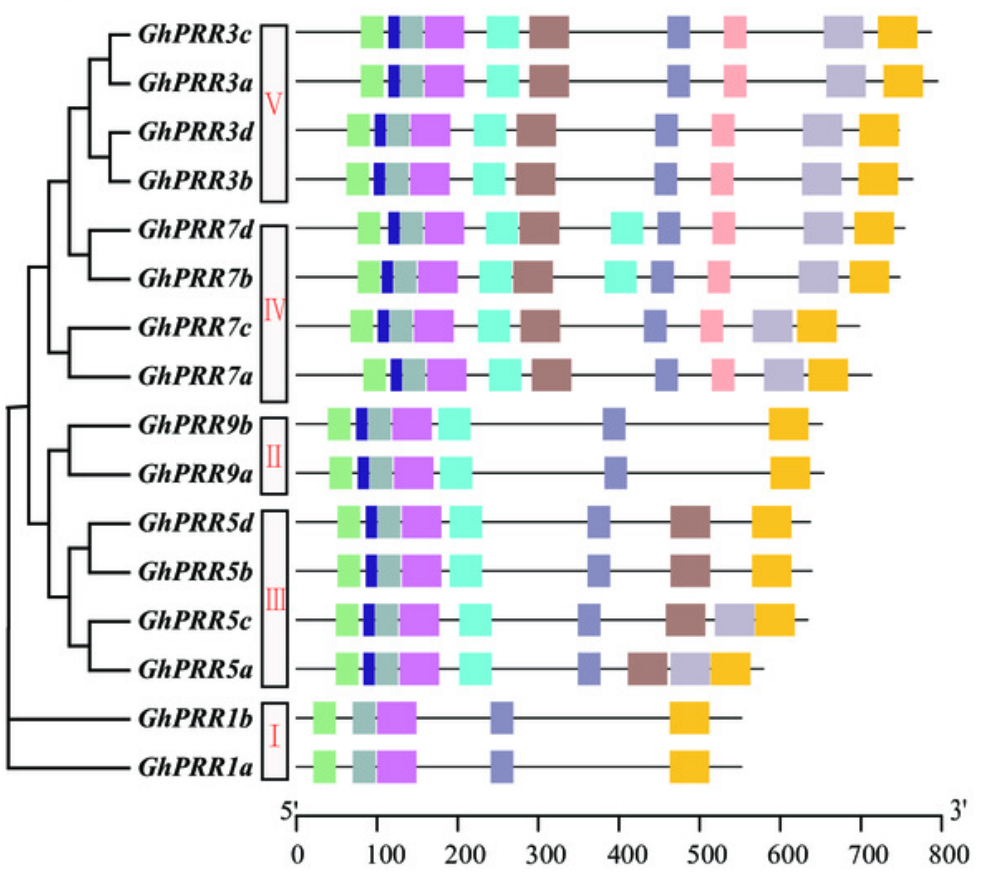

B

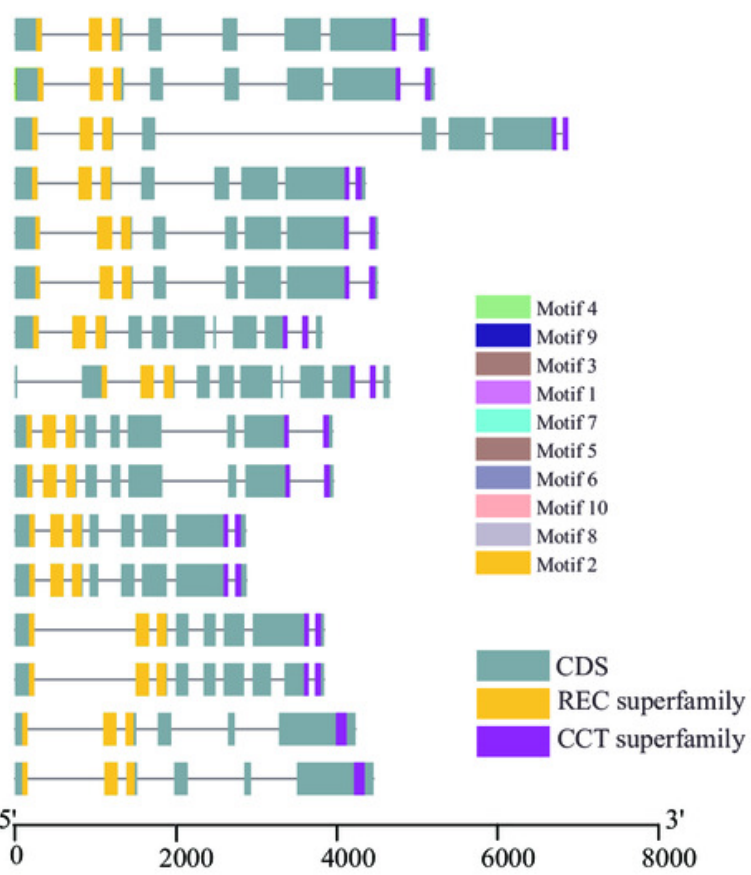

$\mathrm{C}$

auxin-responsive element

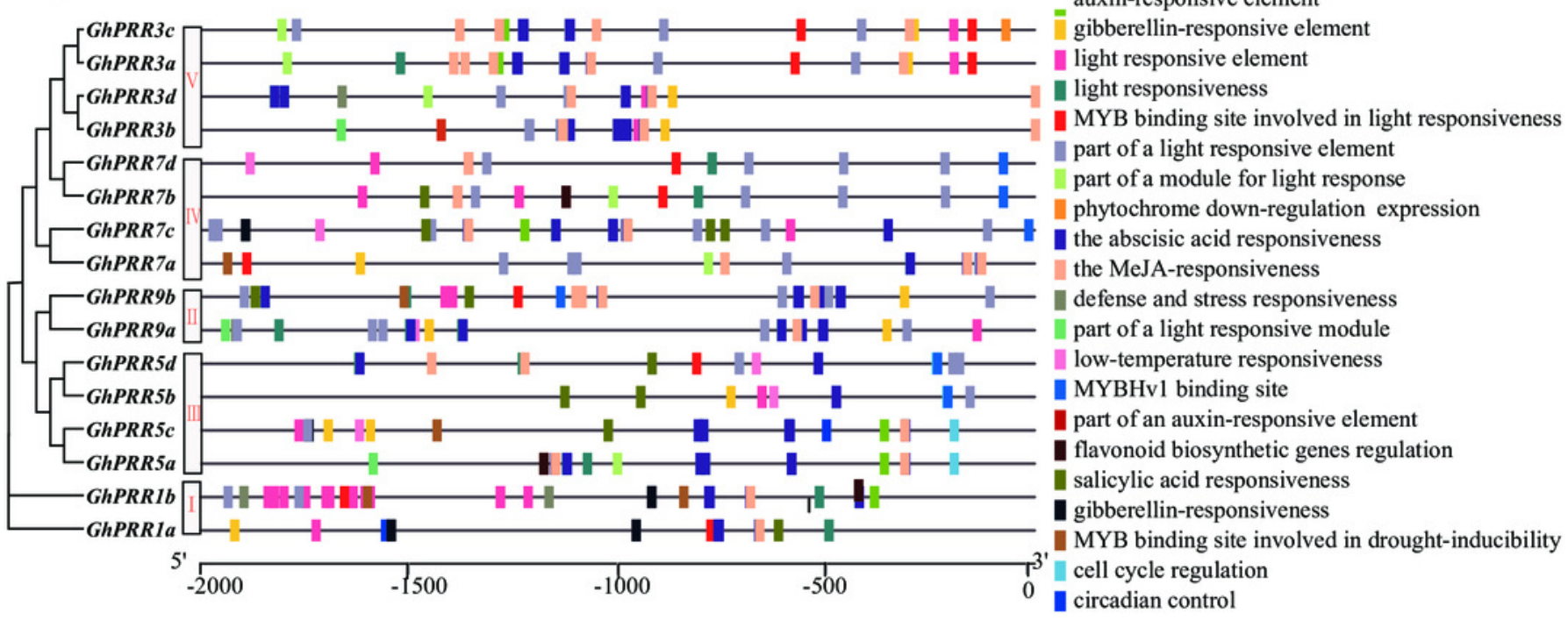


Figure 3

The expression pattern of PRR gene family and related genes during 24 hours in LMY19.

White and black bars on X-axis indicate day and night conditions. Error bars represent means \pm standard deviation $(n=3)$.

A

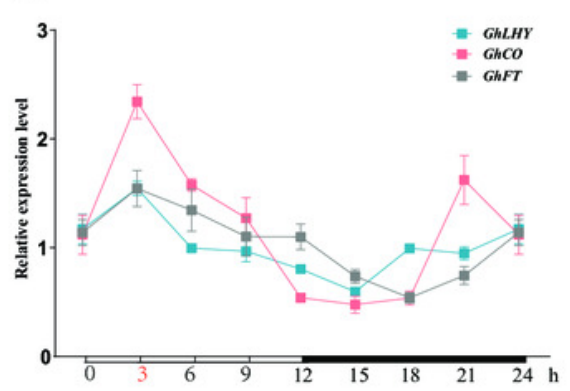

$\mathrm{D}$

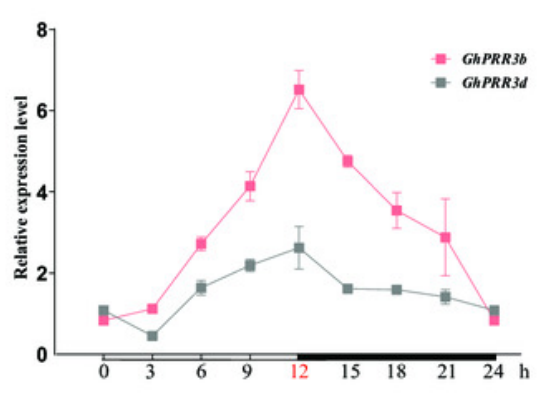

B

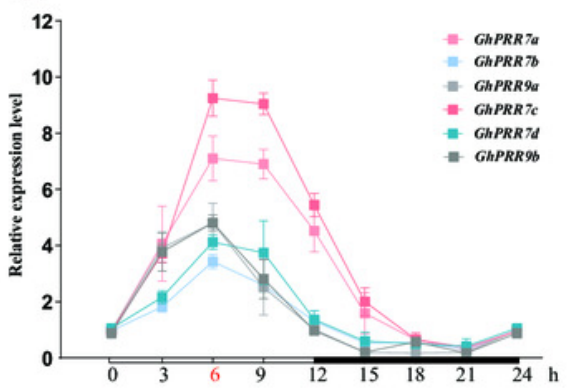

$\mathrm{E}$

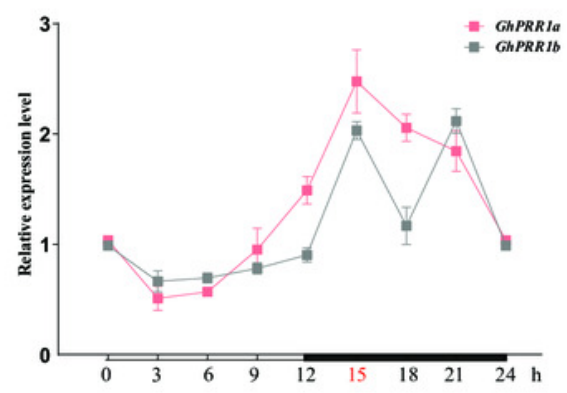

$\mathrm{C}$

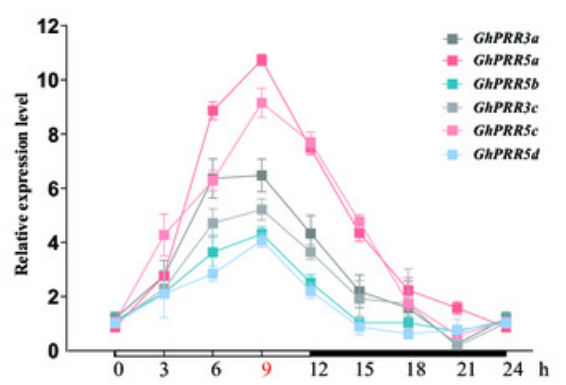

$\mathrm{F}$

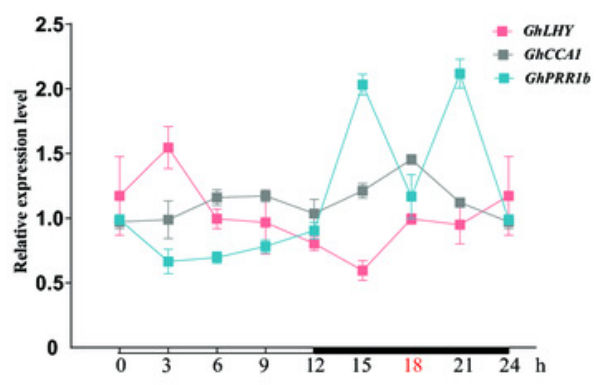


Figure 4

Expression analysis and KEGG enrichment of $P R R$ genes.

(A)Differential expression genes analysis; (B) KEGG pathway enrichment of DEGs PEG_6 $\mathrm{h}$ group; (C)Expression pattern of GhPRR genes with PEG treated at CK, 1, 3 and 6 h. Count sizes of dots correspond to numbers of genes, and their colors correspond to -log10 ( $p$-value) of pathway enrichment. DEGs: differentially expressed genes.

A

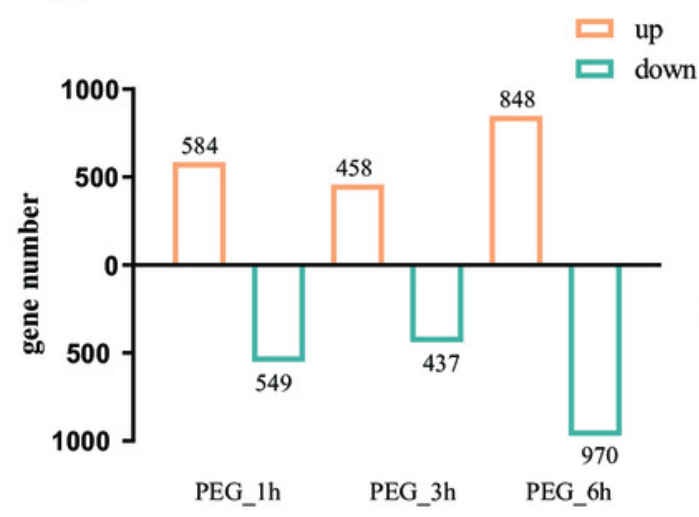

C

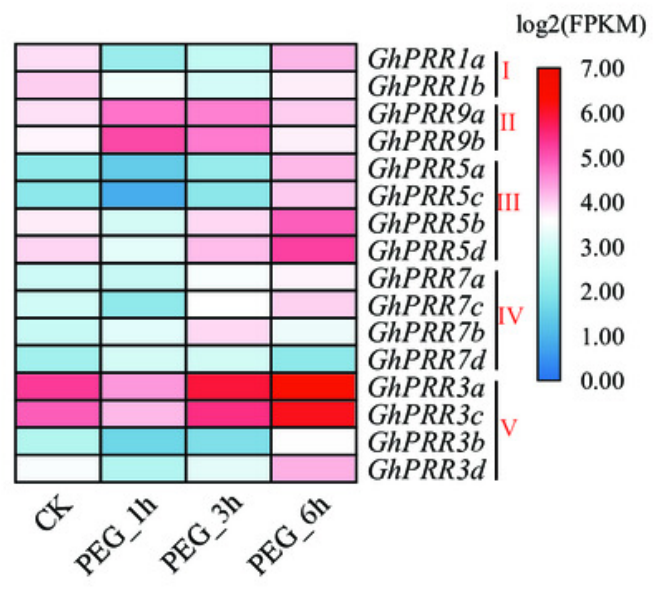

B

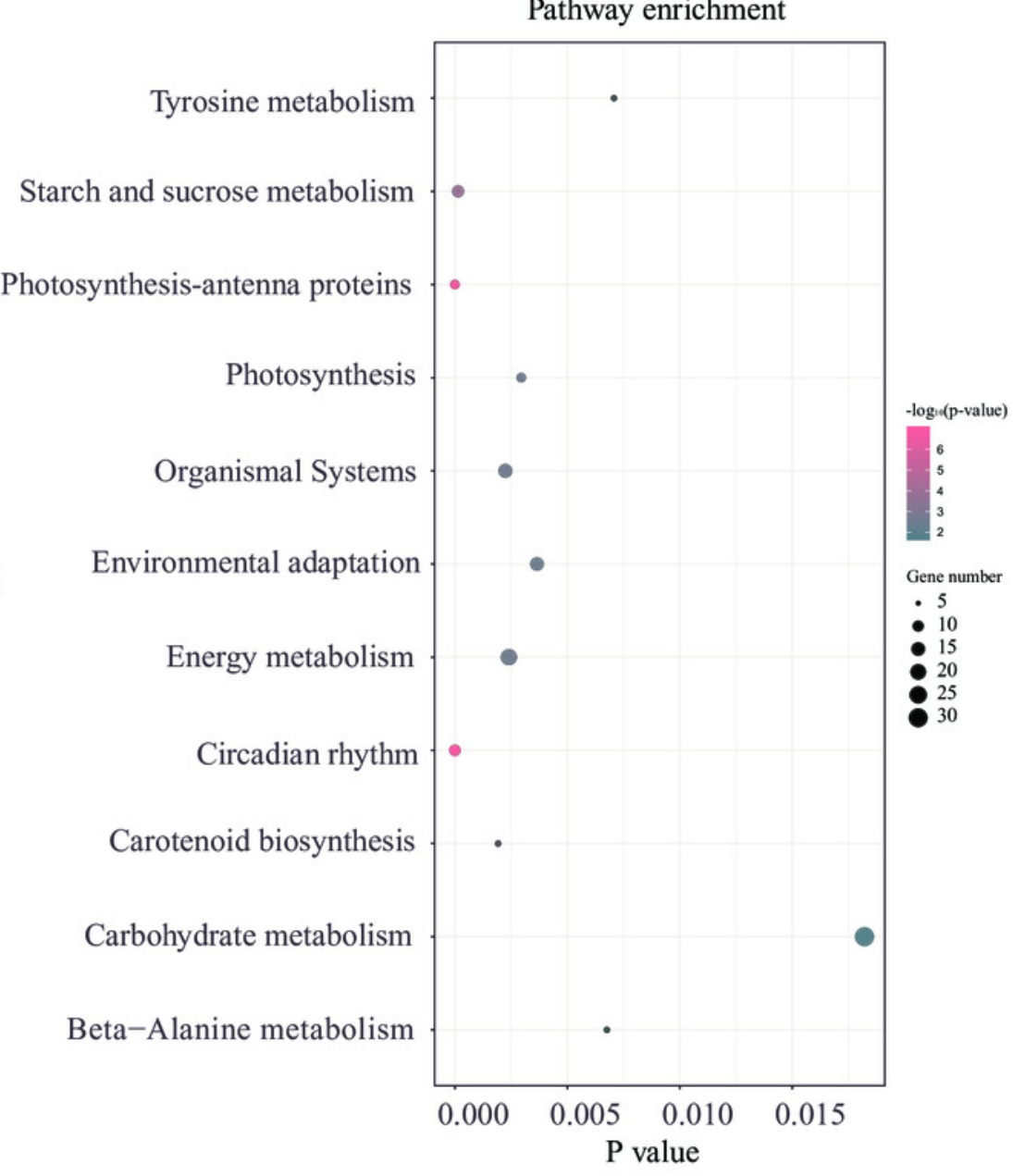




\section{Figure 5}

qRT-PCR analysis of $P R R$ genes under PEG treatment and non-PEG treatment (CK) at 0 , $1,3,6 \mathrm{~h}$.

The * and $* *$ indicate significant differences at $p<0.05$ and $p<0.01$ level, respectively. Differences analysis were compared using one-way ANOVA.
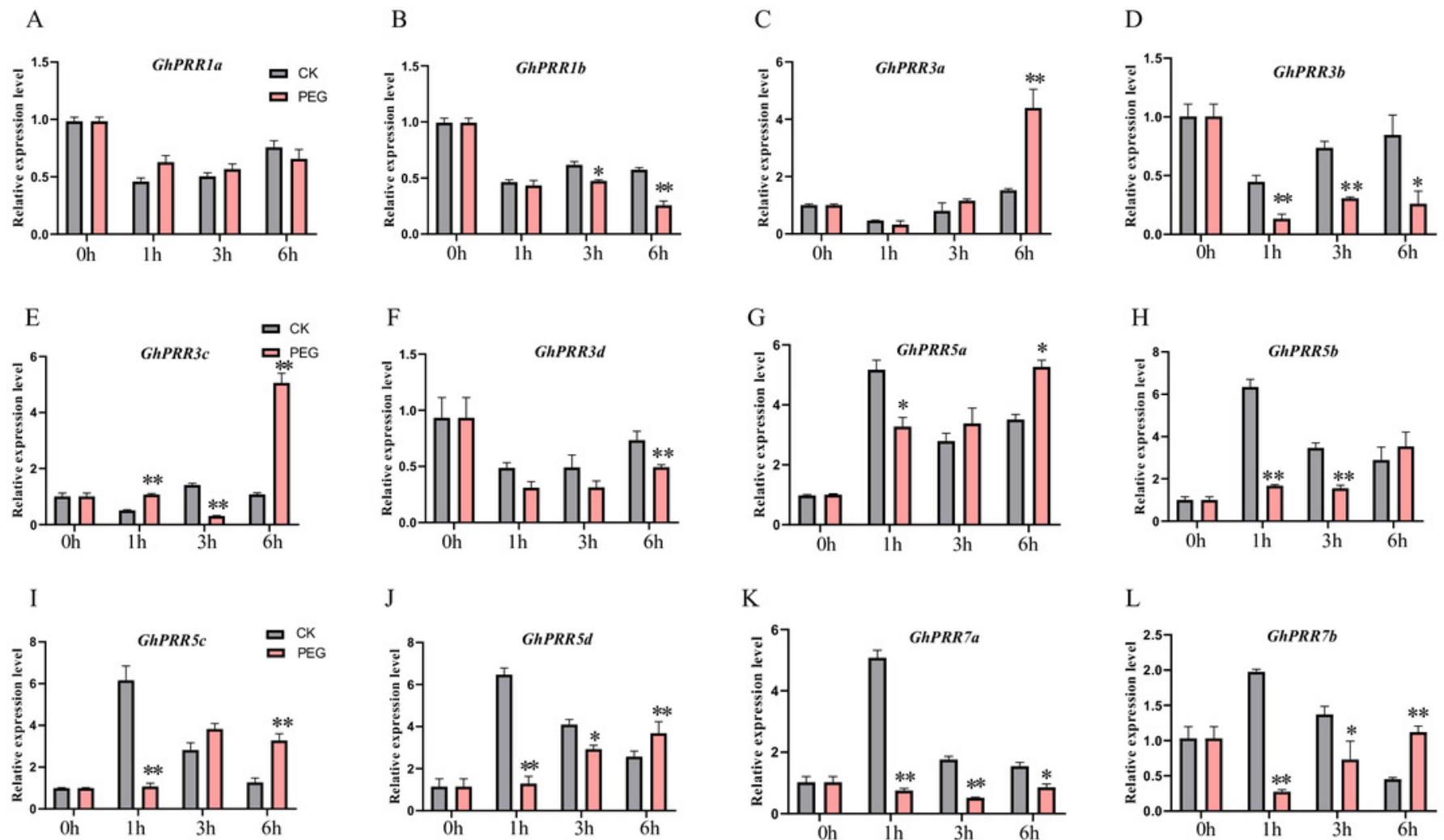

$$
\mathrm{J}
$$
$\mathrm{K}$
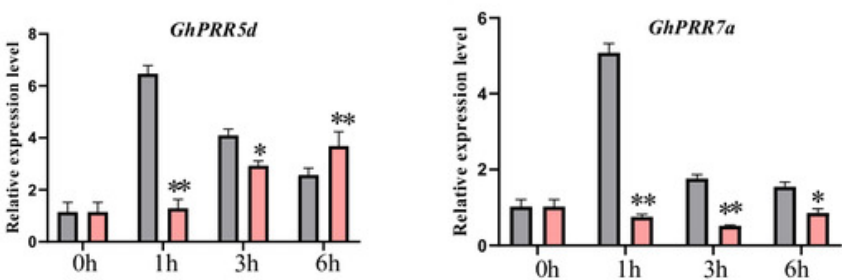

$\mathrm{L}$
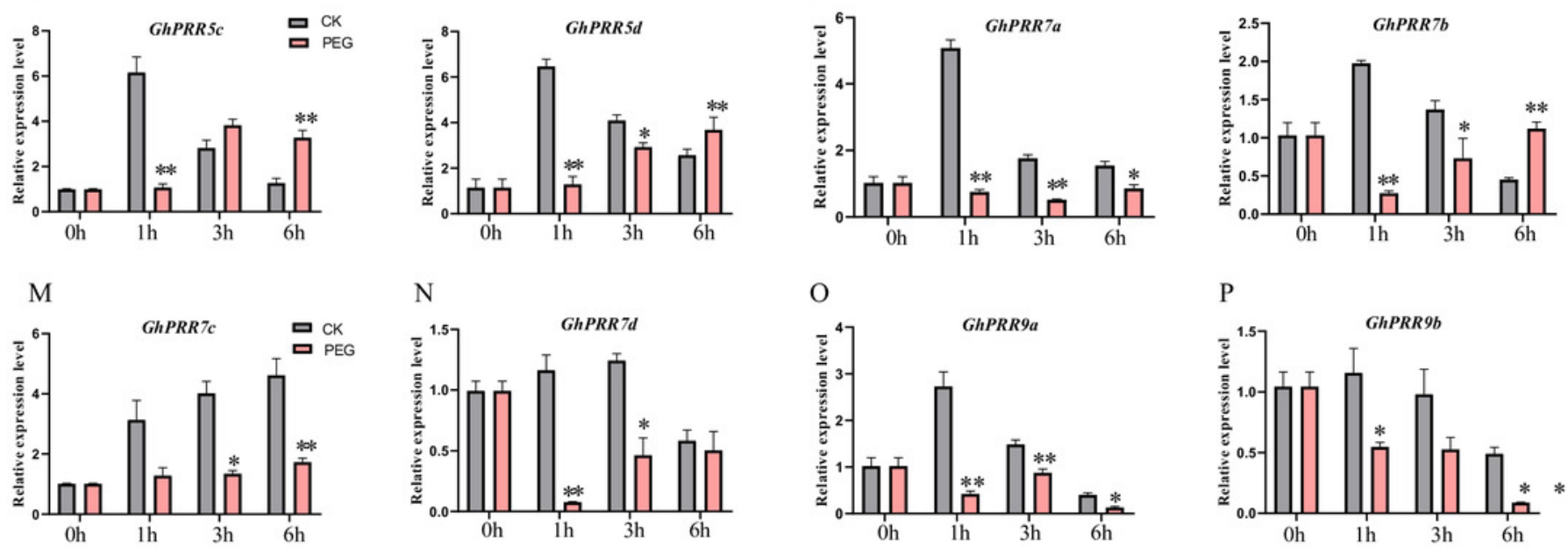